\title{
تسيير التنوع في الموارد البشرية كمطلب لتجنب الصراع التنظيمي
}

\section{الباحثة : القائمة القويـزي، جامعة البليدة، الجزئر}

\begin{abstract}
تعالج هذه الورقة البحثية اشكالية تسيير تنوع القوى العاملة في مكان العمل ودوره في

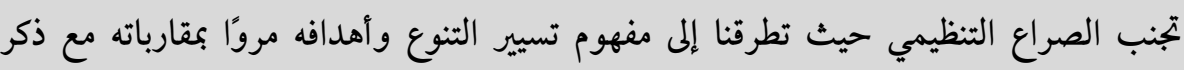

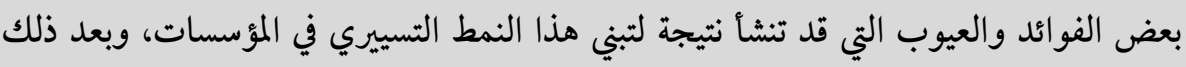

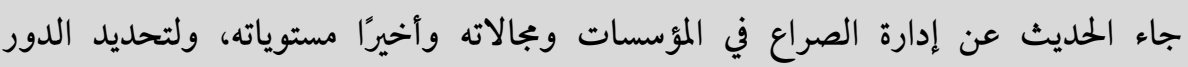

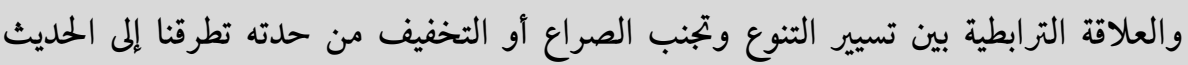

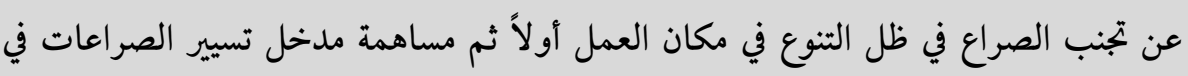

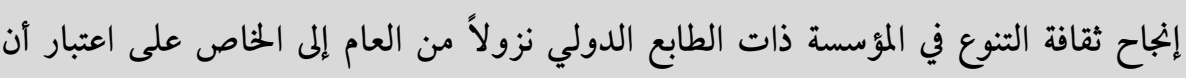
تسير التنوع أساسًا لتجنب وخفض حدة الصراع التنظيمي.
\end{abstract}

\section{Abstract :}

This paper dealt with the problematic conduct of the diversity of the workforce in the workplace and its role in avoiding organizational conflict where we dealt with the concept of management of diversity and its objectives through the approaches with mention of some of the benefits and disadvantages that may arise as a result of the adoption of this administrative in institutions pattern and then came to talk about the conflict in enterprise management and the fields and finally levels, and to determine the role and the relationship relational between the conduct of diversity and avoid conflict or mitigate touched to talk about avoiding conflict in diversity in the workplace first and then the contribution of the entrance to the conduct of the conflicts in the success of the culture of diversity in the organization of an international character down from the general to the specific on considering that going mainly to avoid and reduce unit organizational conflict. 


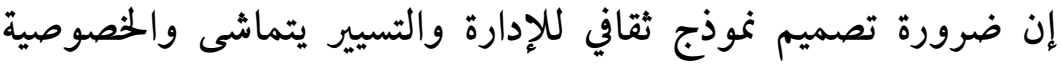

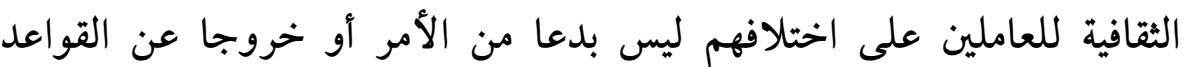

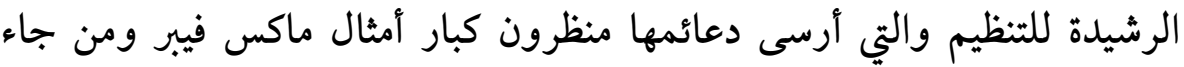

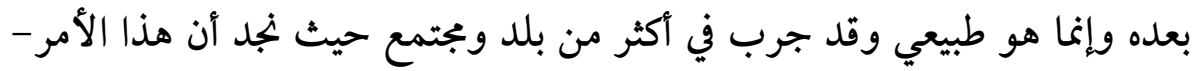

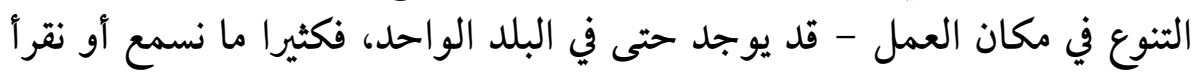
عن اختلاف العاملين من منظمة إلى أخرى.

بل أننا نجد حتى في المنظمة الواحدة من يتحدث عن إدارة الموارد البشرية

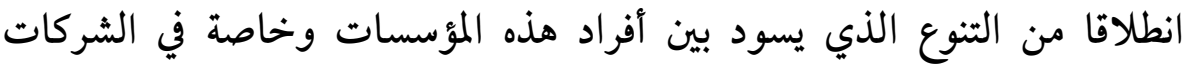

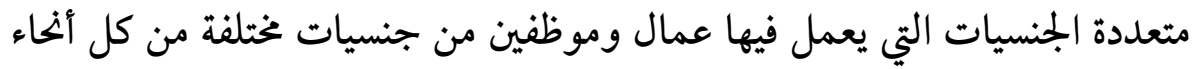

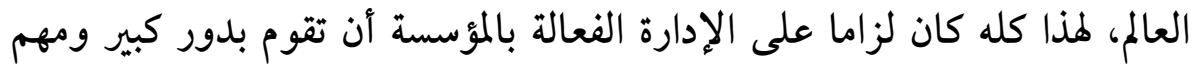

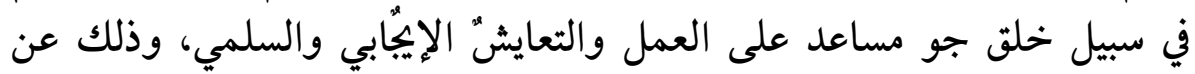

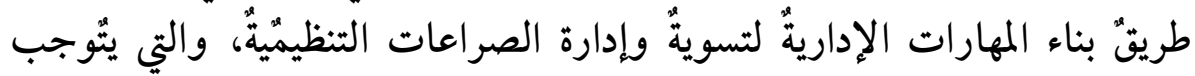

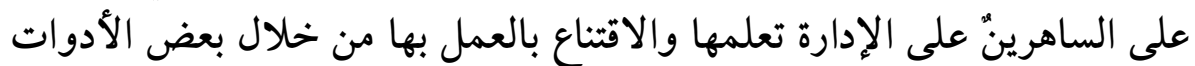

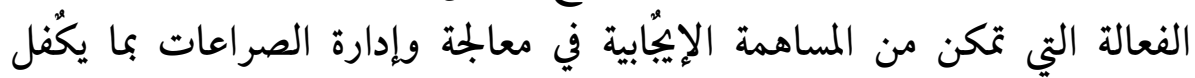
تحقيق" أعلى درجات الفعاليةٌ التنظيمية.

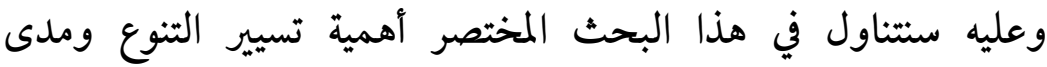

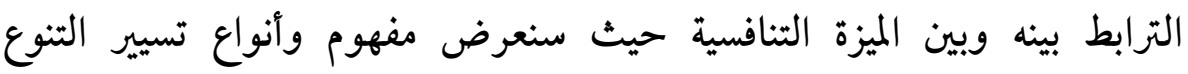

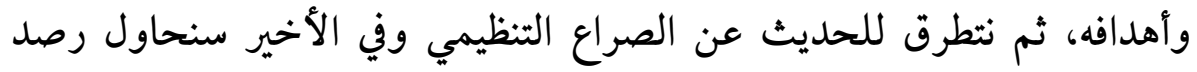

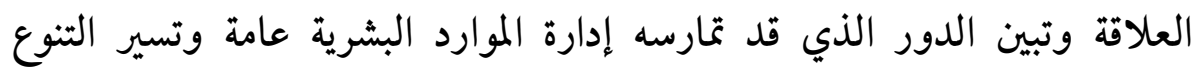
خاصة في تجنب وخفض حلدة الصور الذي قداع التنظيمي في المؤسسة.

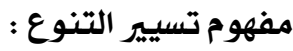
تسيير التنوع هو عملية مستمرة لإدارة الاختلافات بين الموارد البشرية

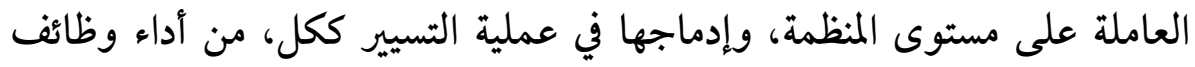


وخدمات واتصالات وعمليات، بهدف خلق منظمة أعمال عادلة، شاملة متناغمة

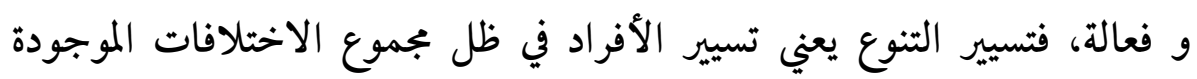

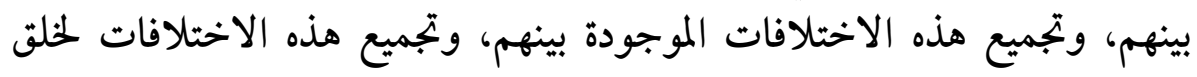

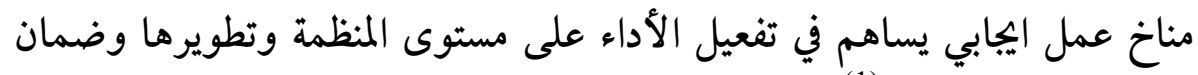

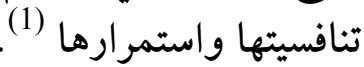

كما يعني تسيير التنوع " تمكين القوى العاملة المتنوعة من تنفيذ إمكانياتها

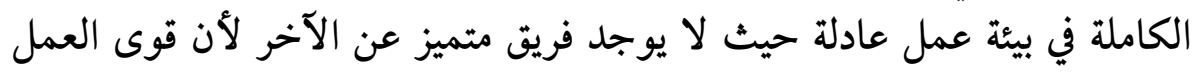

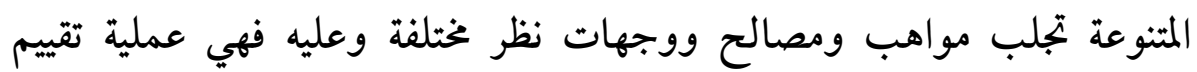
مستمرة للاستفادة من الفروق الفردية كي يتسنى لجميع الأفراد تعظيم قدراتهم في وفي فئي

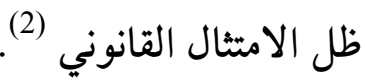

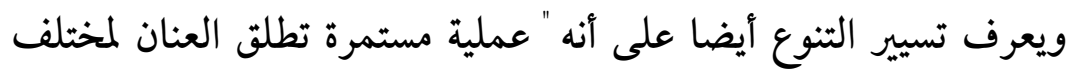

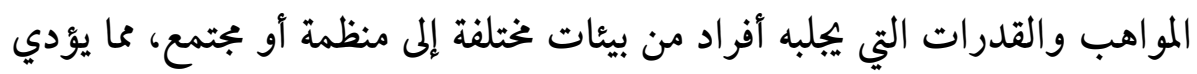

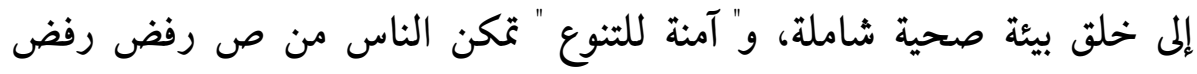

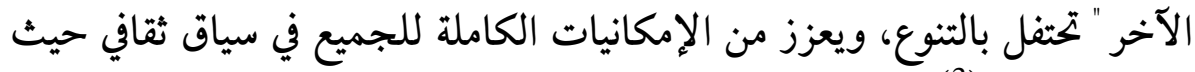
يستفيد الجميع '3).

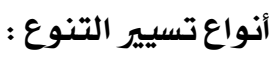

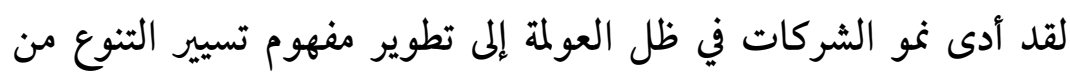

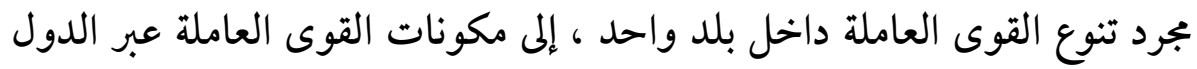
وعليه يمكن تحديد نوعين من تسيير التنوع هما: (cross - nations)

> تسيير التنوع الدولي (International diversity management): وتعني تسيير قوى عاملة متنوعة من المواطنين والمهاجرين في سياق المنظمات من

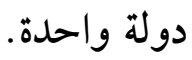

> تسيير التنوع عبر الوطنية (Cross - national diversity management) : وتعني تسيير قوى عاملة مكونة من مواطنين ومهاجرين في دول بختلفة التينة 
مثال: شركة كورية لما فروعها في الصين وماليزيا واليابان، تضع سياسات

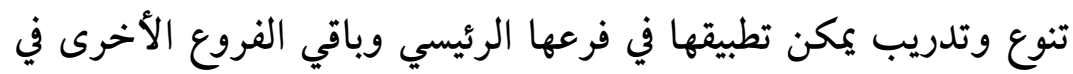

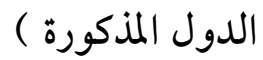

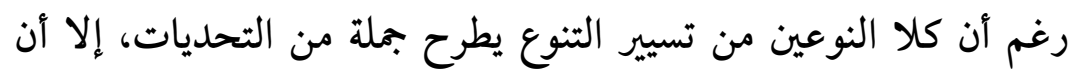

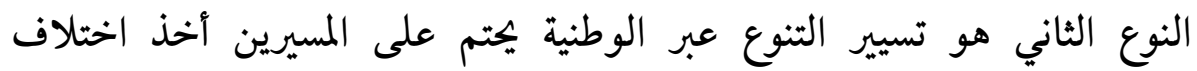

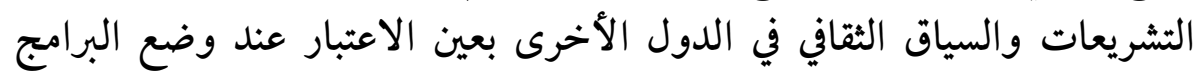
والثقافات وعليه فإن تحدياته أكبر. خصائص وأهداف تسيير التنوع :

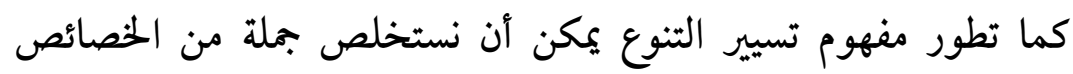

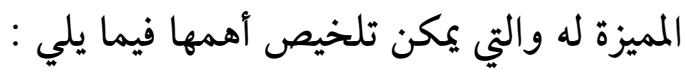

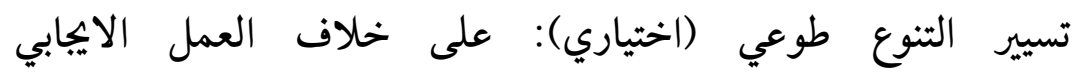

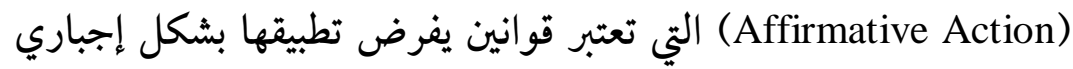

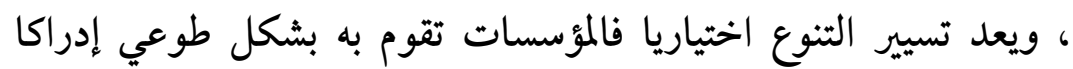

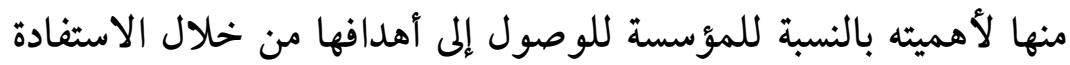

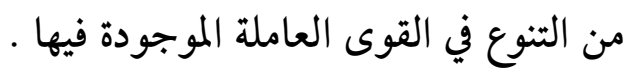

تسير التنوع يستخدم مفهوم موسع لمفهوم التنوع : فعلى خلاف العمل

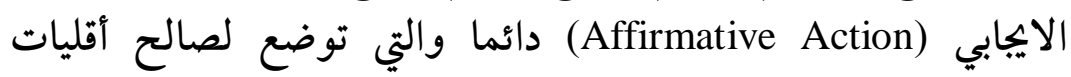

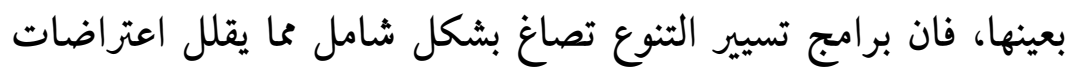

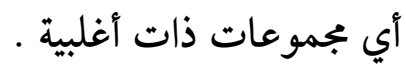

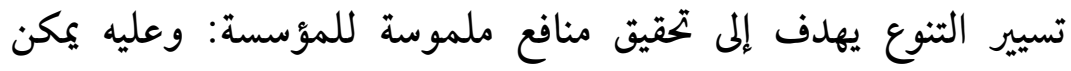

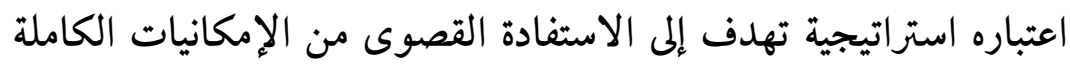

لجميع الموظفين بهدف إعطاء المؤسسة ميزة تنافسية (4). وبناءا على الخصائص السابقة يككن القول بأن تسيير التنوع يهدف إلى : 


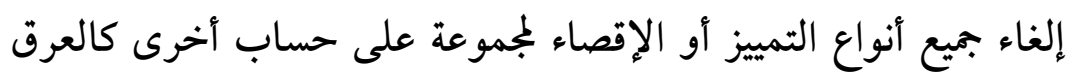
أو الجنس أو الجنسية أو أية خصائص أنواع أخرى. الأحصاء

تثمين الفرو قات بين العاملين ومحاولة تعظيم الاستفادة منها لصالح تحقيق أهداف المؤسسة . تصنين

كسب الحرب على المواهب" war for talents "للحصول على أحسن

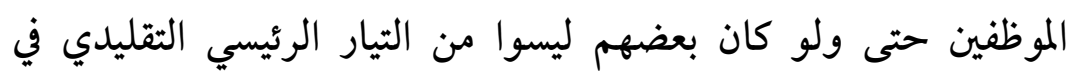

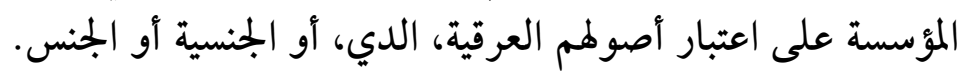
الاستفادة من فرق الإدارة غير المتجانسة والتي تميل إلى خلق قوة ابتكار

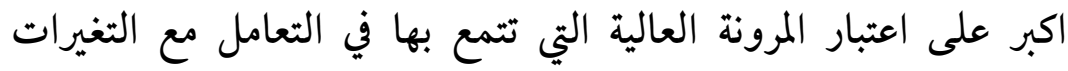
الخارجية على عكس فرق الإدارة المتجانسة .

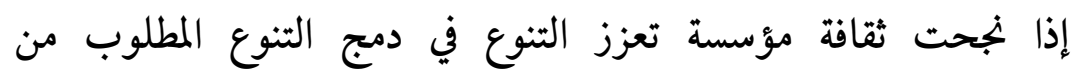
الموظفين، فان هذا سيرفع من تحفيز ورضا العاملين ويقلص من خؤنس خسائر

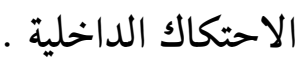

الشركات ذات إدارة التنوع الفعالة تستفيد بشكل أفضل من أسواقها

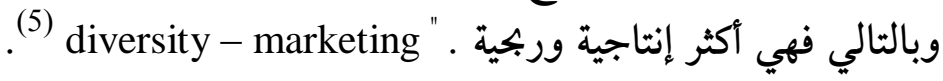

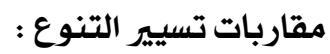

يتم تبني جملة من المقاربات لتسيير التنوع تختلف باختلاف إدراك مفهوم

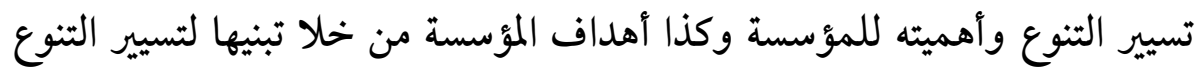
في حد ذاته كمقاربة تسيرية، وفي هذا السياق سنحاول التركيز على أهم هذه المقاربات والتي يمكن تلخيصها في الجدول التالي : 
جدول رقم (01) : يبين مقاربات تسيير التنوع في الموارد البشرية

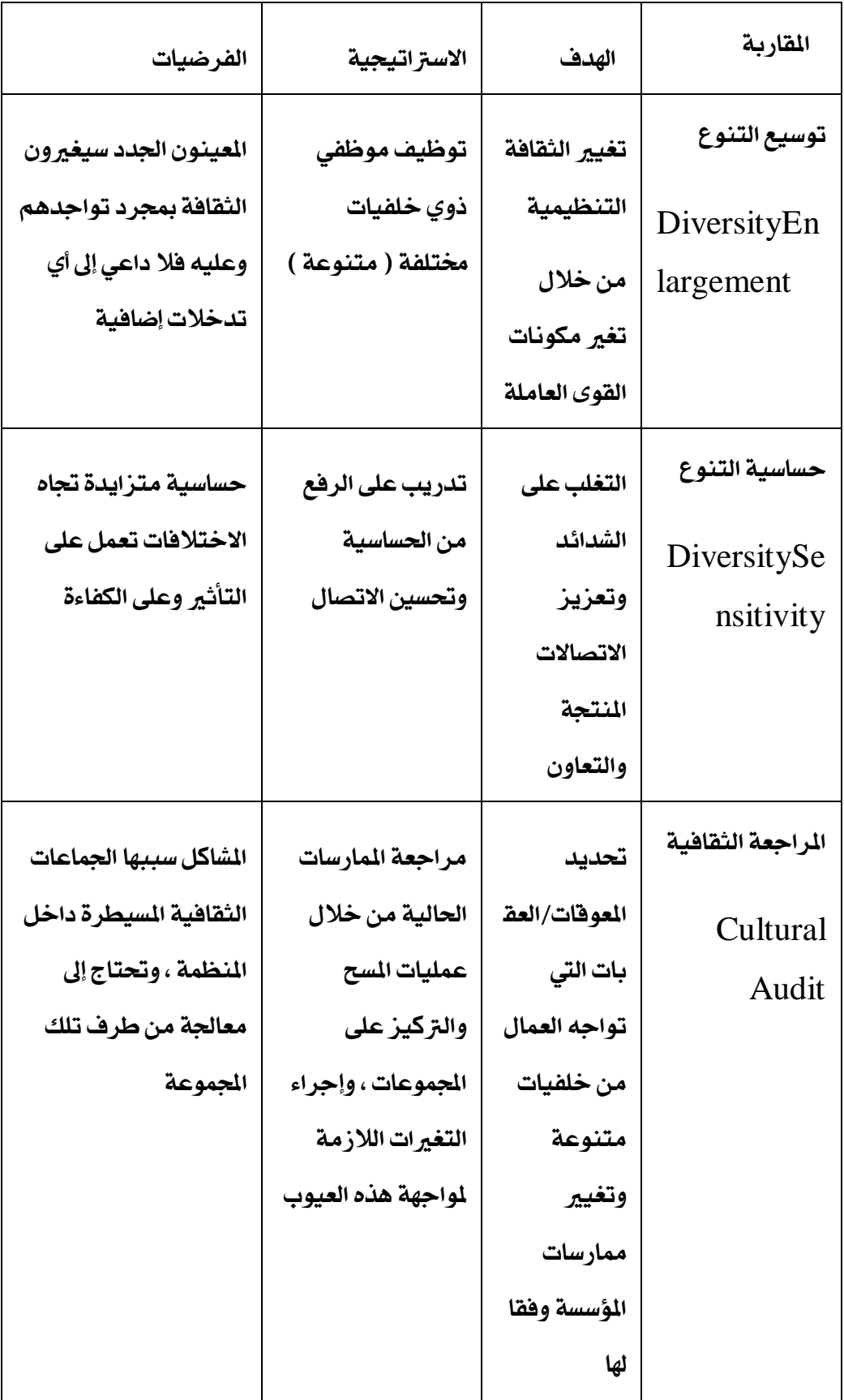




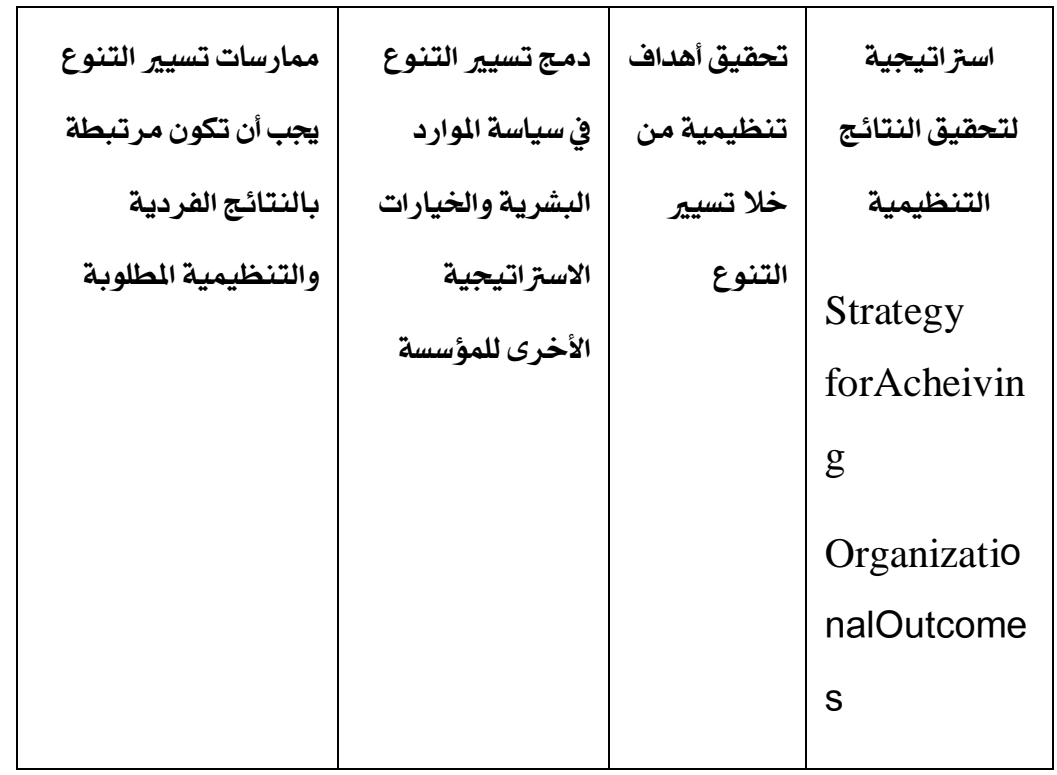

Source : CHAPTER 10 ,Diversity Management, Paradigms ,Rationale and Key Elements ,p 242, available on www.sagepub .com / upm - data /35190_ Chapter 10 pdf .

1-توسيع التنوع DiversityEnlargement : يشير توسيع التنوع لمحاولات زيادة تمثيل الأفراد من الجنسين، والعرقيات والخلفيات الثقافية المختلفة في المؤسسة، لأنه

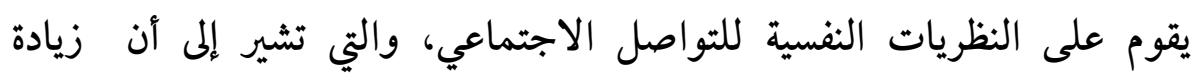

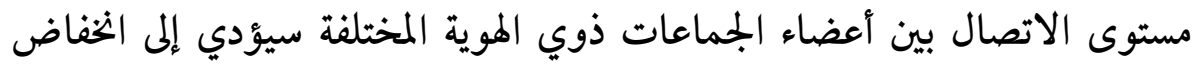

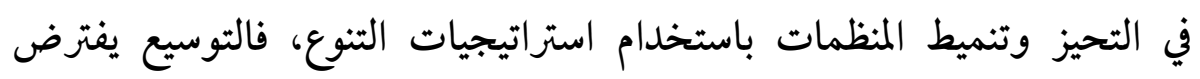

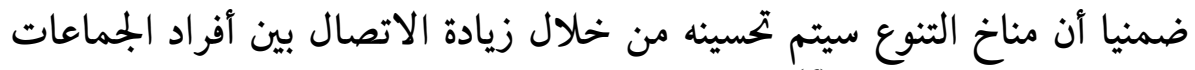
مختلفي الموية الاجتماعية (6) - حساسية التنوع Diversity Sensitivity: هي حساسية واستعداد السلوك الخاص للتكيف واستيعاب الاختلافات الموجودة في بيئات العمل المتنوعة عن هن

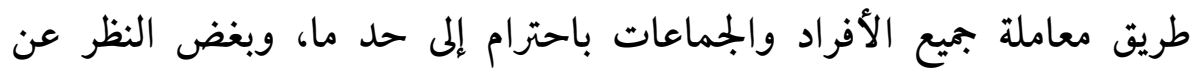




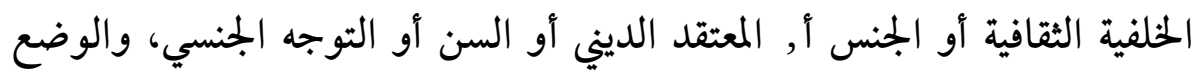

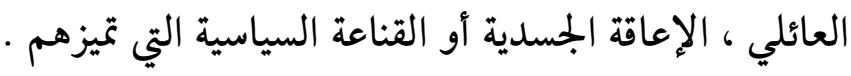

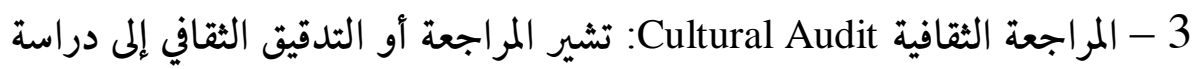

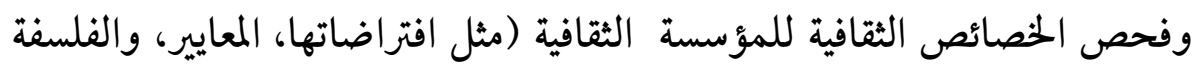

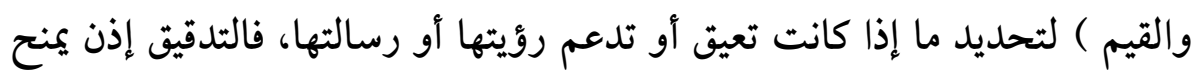

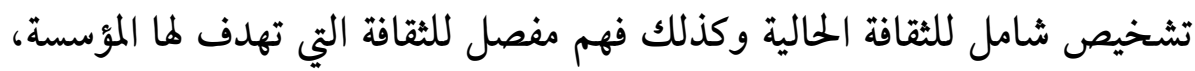

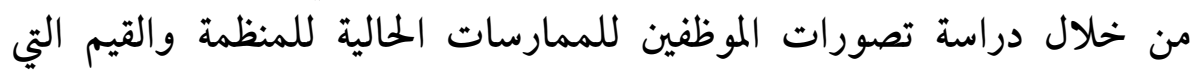

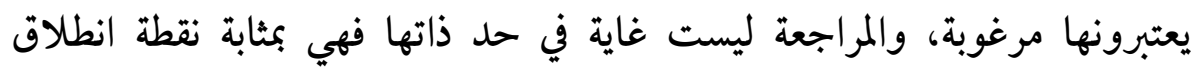

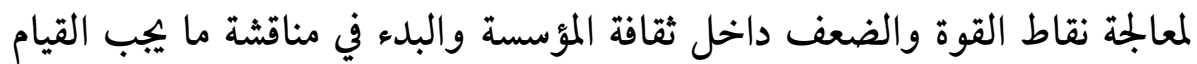
به لتسهيـل التغيير التنظيمي (7). 4trategy for Achieving بإستراتيجية لتحقيق لنتائج تنظيمية أمداف تونيمة: OrganizationalOutcomes

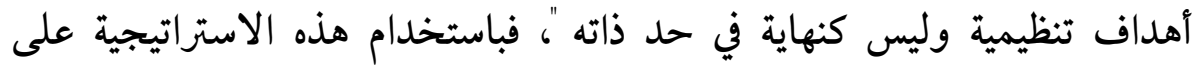

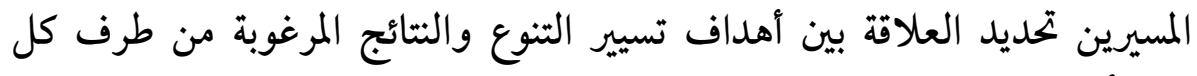

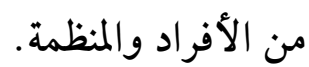

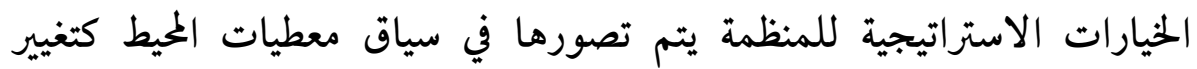

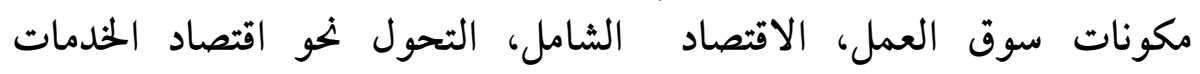

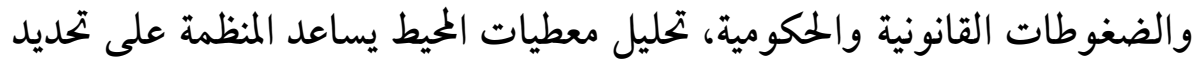

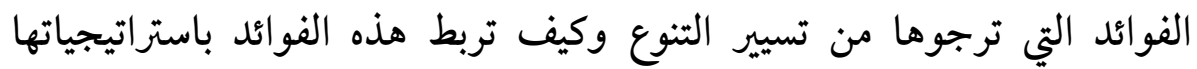

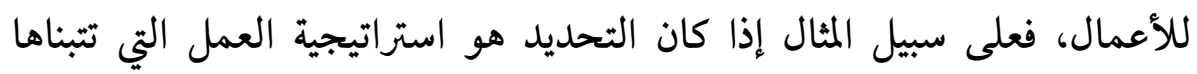

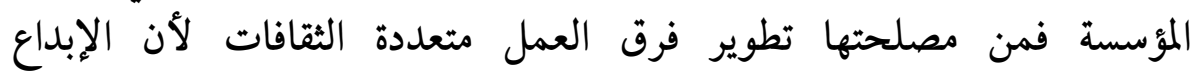
والاستجابة الجيدة للأسواق الجديدة نجدها أحسن في فرق فرق العمل المتنوعة (8). 
فوائد التنوع في مكان العمل :

الفوائد الداخلية للتنوع : بناءا على دراسات الحالات فإن الفوائد التي

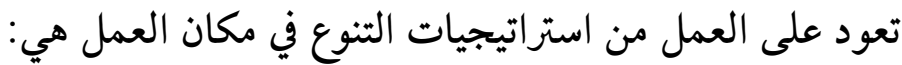

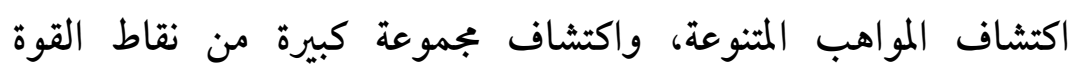
والخبرات الفردية افت الموات استخدام وجهات النظر المختلفة والأفكار لزيادة الإبداع والابتكار

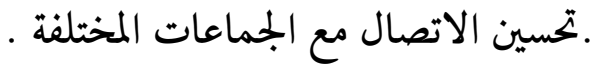
بناء أفضل الممارسات وانخفاض معدل دوران العاملين، وزيادة الحماس الحس والتحفيز والقدرة على المنافسة . لماء المصن الحد من الغياب والإجازات المرضية وزيادة الإنتاجية والربحية . إنشاء سياسة التنوع هودليل على التزام المسؤولية الاجتماعية للشركة .

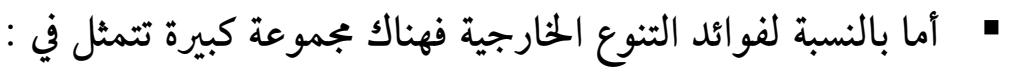
• تحسين صورة المنظمة وتقوية العلامة التجارية للشركة وتحسين خدمة

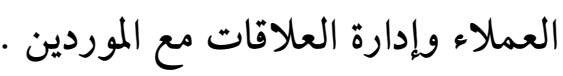
فهم أكبر لاحتياجات ومتطلبات قاعدة عملاء متنوعة بشكل متزايد مع فتح أسواق جديدة محتملة . ورغم الفوائد المذكورة آنفا لإدارة التنوع إلا أن هناك تباينا حول مدى التى

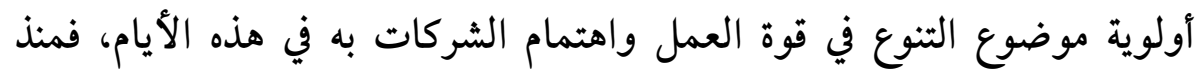

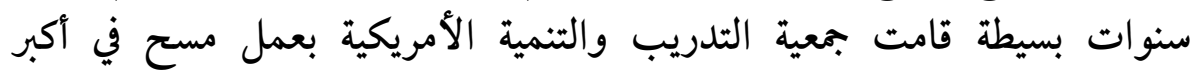
1000 شركة أمريكية عن مدى الاهتمام بموضوع التنوع، واتضح من نتائج المسح

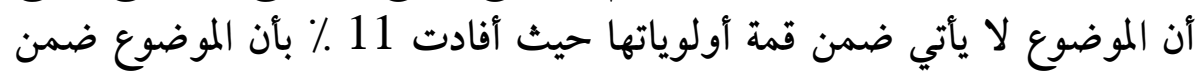
قمة أولوياتها. كما أفادت 33٪ بأنها بدأت تفكر في الموضوع وبوجه عام فإن حوالي

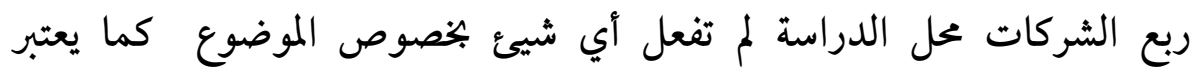




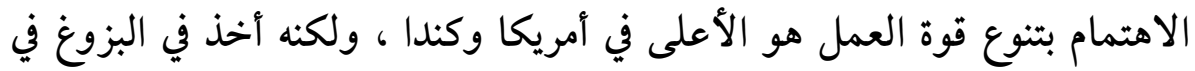

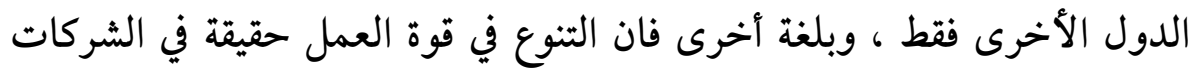

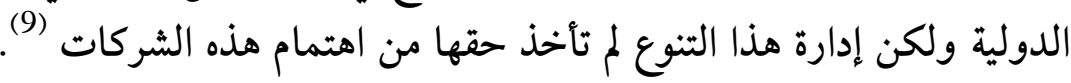

وتحقق إدارة تنوع الموارد البشرية في المؤسسة عدة مزايا نذكر منها كما وردت

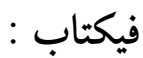

"comment réussir la politique de la diversitédans l'entrep-rise l'entreprise, cahier d'entreprises $n: 3, p: 4 "$

ل تنمية الكفاءة الاقتصادية للمؤسسة:في إطار اقتصاد المعرفة فإن إدارة

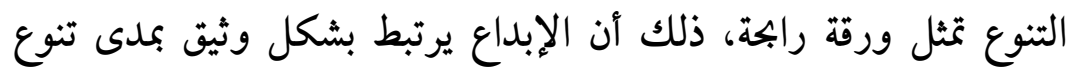

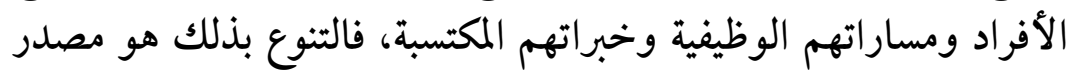
الإبداع والابتكار.

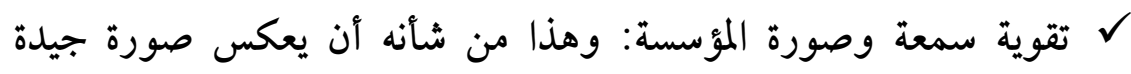

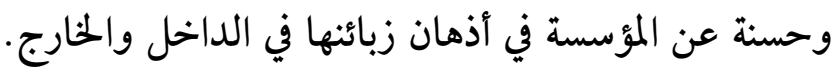

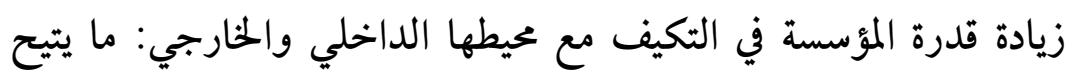

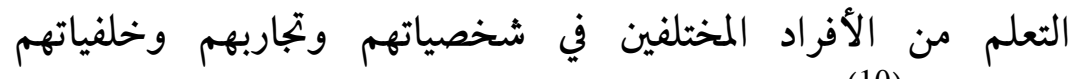

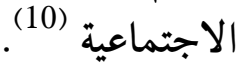

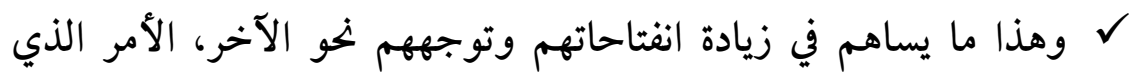

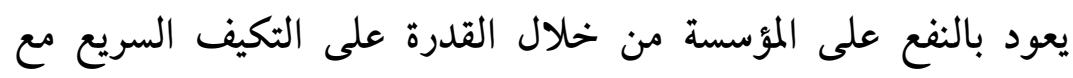

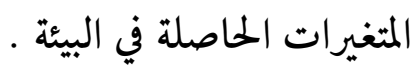

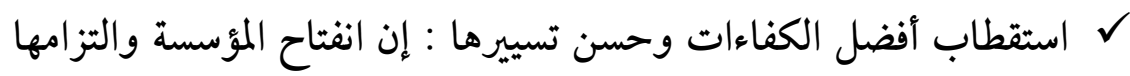

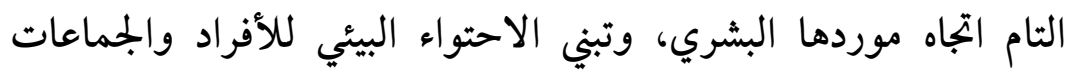

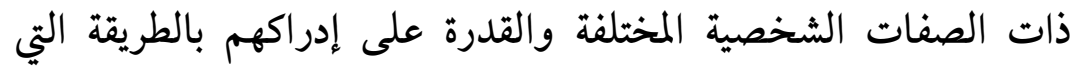

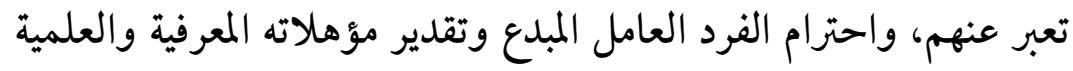
واعتبارها المعيار والمحدد الأساسي للتوظيف المراع وكذا الثوجه في الاستثمار 
وتنمية رأس المال البشري، كل هذا من شأنه أن يبعل المؤسسة قبلة لتهافت أفضل الكفاءات . تسمح إدارة التنوع بترقية القيم الثقافية للمؤسسة عبر رفض ونبذ كل

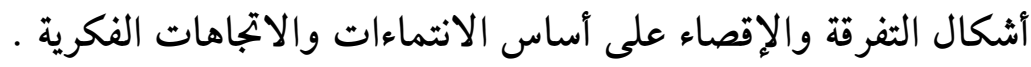

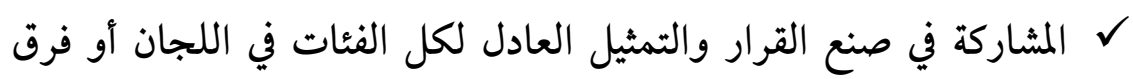
العمل سيؤدي إلى تحفيزهم ودفعهم إلى مزيد من الإنتاج.

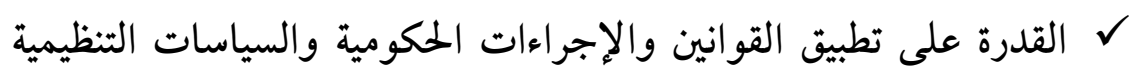

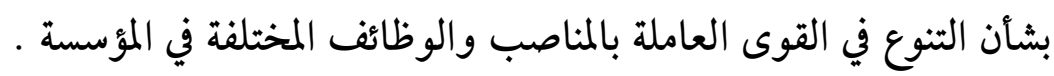
زيادة مرونة المؤسسة عل مواجهة الأزمات والمواقف الصعبة بوجه عام

ل تحقيق ميزة تنافسية أفضل للمؤسسة في السوق وزيادة القدرة على جذب المب المبدة

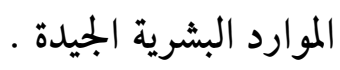

زيادة القدرة على العمل إنتاجا وتسويقا وكذلك التنوع في الأفكار والإبداع والابتكار والقدرة على حل المشكل المكلات. ل زيادة مرونة المؤسسة لمواجهة المشاكل بوجه عام (12). ل جذب أفضل المواهب للمساهمة في الأعمال : وبالتالي تكون المنظمة

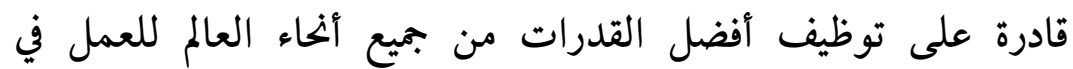

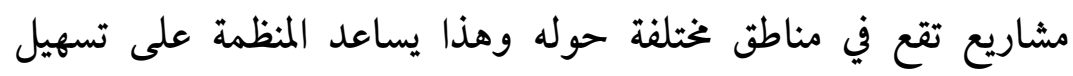

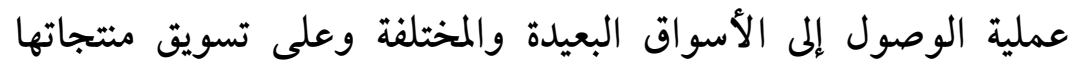

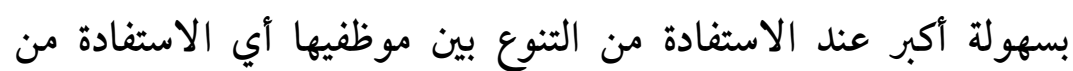

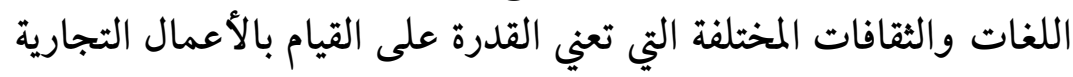

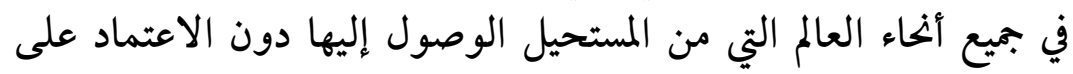

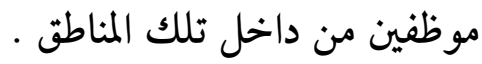


بناء موارد بشرية ذات تنافسية عالمية:بناء نموذج مصغر عن العالم في مكان العمل

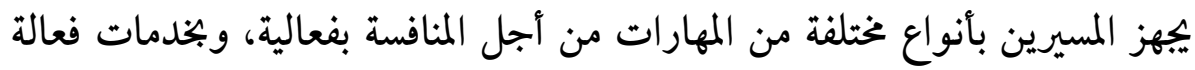

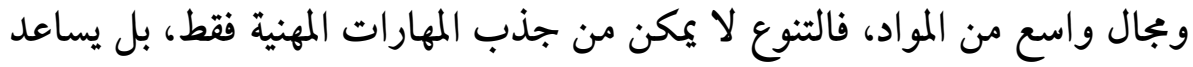

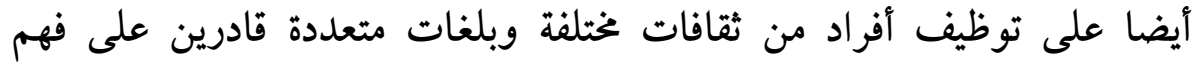

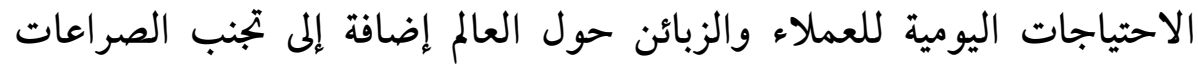

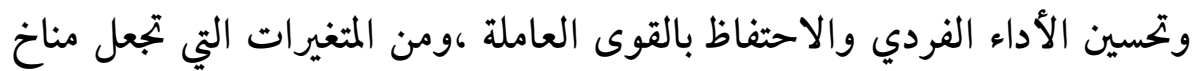

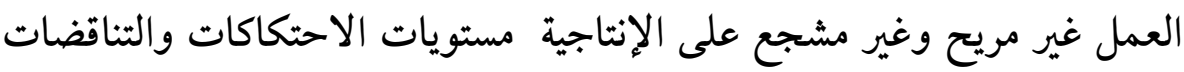

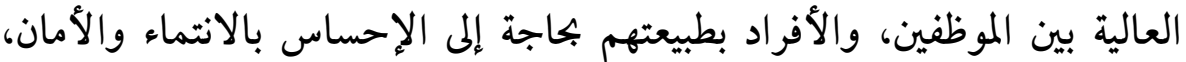

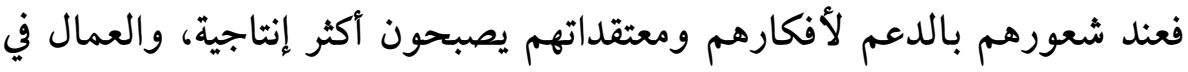

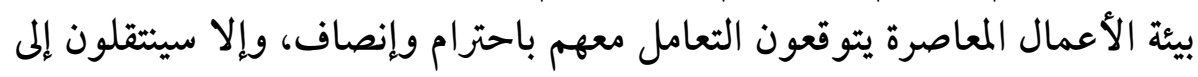

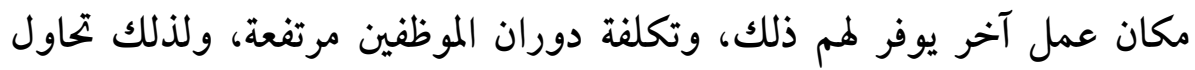

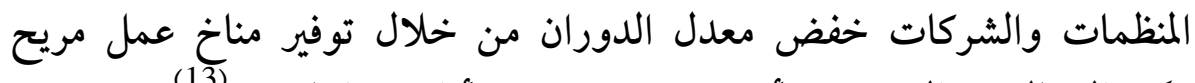
يككن العمال من التعبير عن أنفسهم ويضمن رفع أدائهم وإنتاجهم (13). عيوب ومساوئ التنوع في مكان العمل :

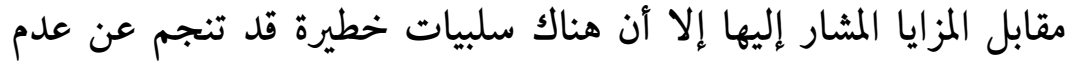

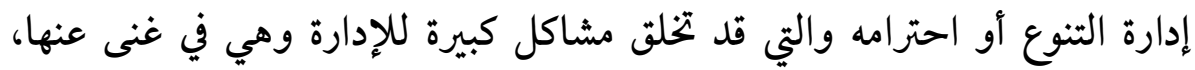

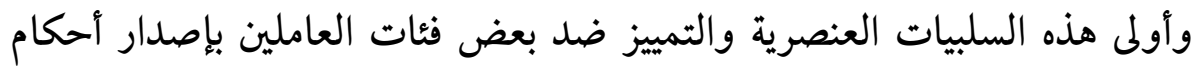

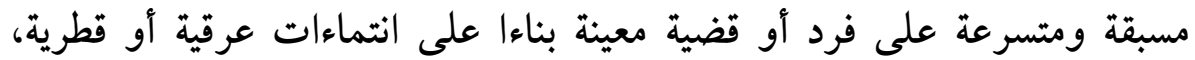

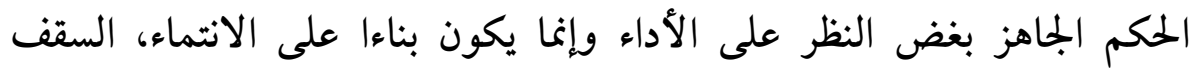

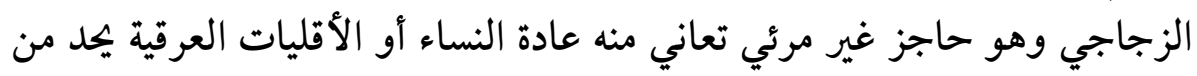

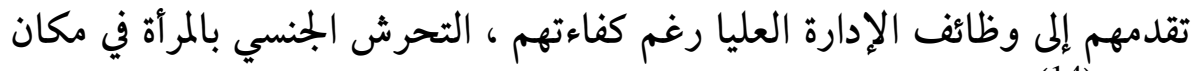

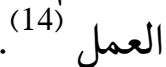

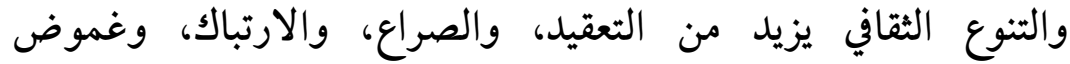

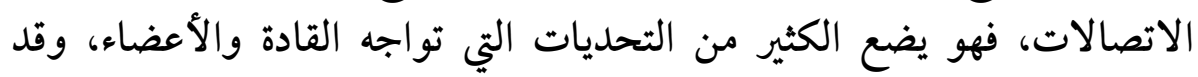

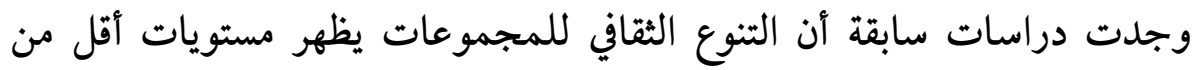


التكامل والتماسك كما أن عدم وجود عقليات و نماذج مشتركة يمنع التفاهم بين

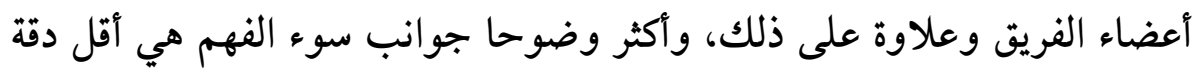

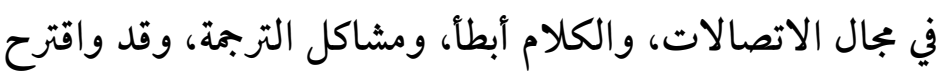

Barna, Stumbling blocks in intercultural communication, in L.A.Samovar,R.E. Porter (Eds.)

Intercultural Communication: A Reader, 4th ed., WadsworthPublishing Company, Belmont, CA, 1985, pp. 330-337.

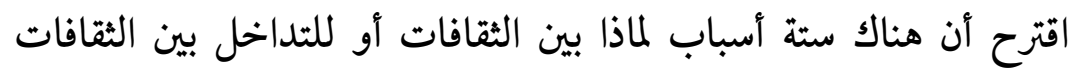

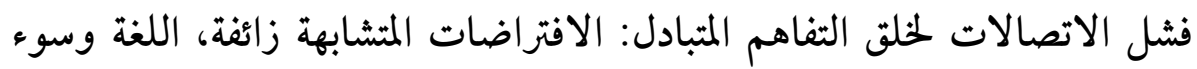

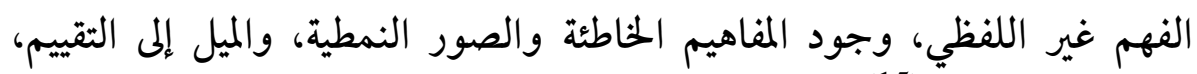
وجود عالي للقلق (15).

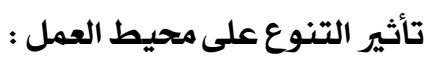

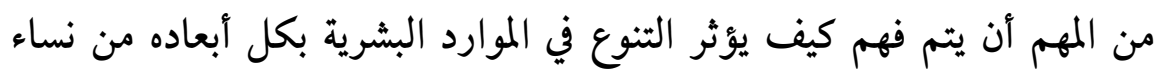

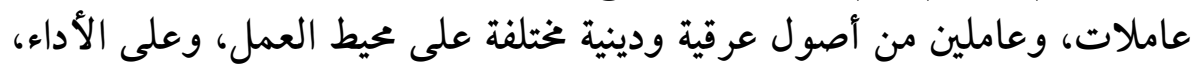
التحفيز، لتفاعل مع الآخرين، والنجاح في النهاية : عامرين ودينة

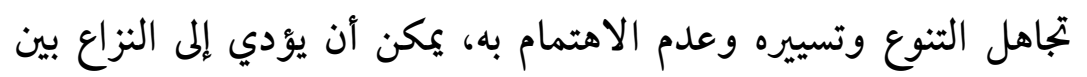

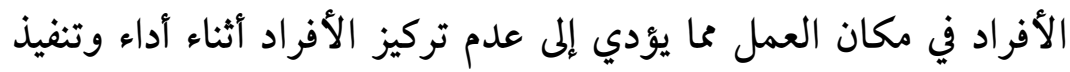

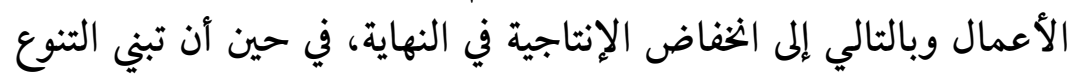

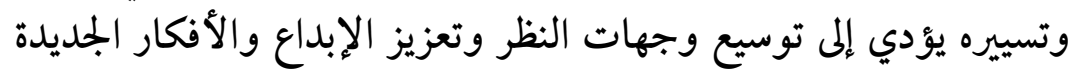
،وبالتالي توفير فرص إضافية لزيادة العملاء والزبائن .

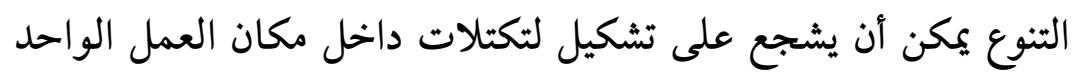

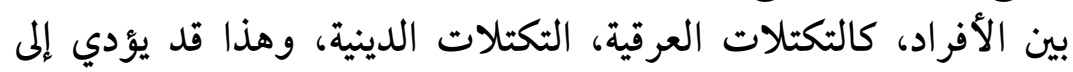

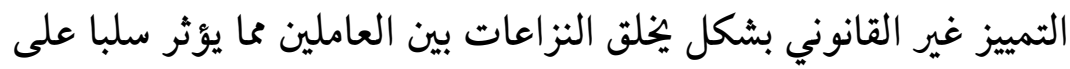

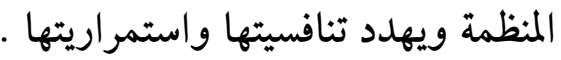


القدرة على تقييم الفروق الفردية يؤدي إلى قبول أكبر لجميع وجهات النظر، مئا

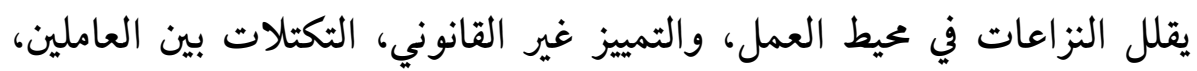
وهذا كله يؤدي إلى توفير محيط عمل مريح ومشجع على العيد الإبداع وتحسين الأداء

\section{مفهوم الصراع التنظيمي:}

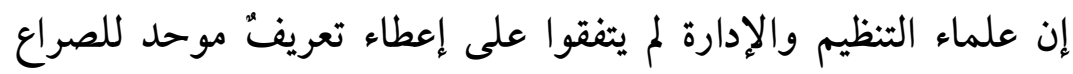

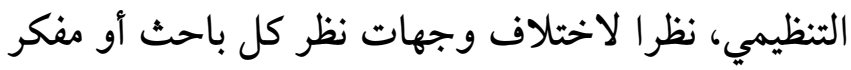

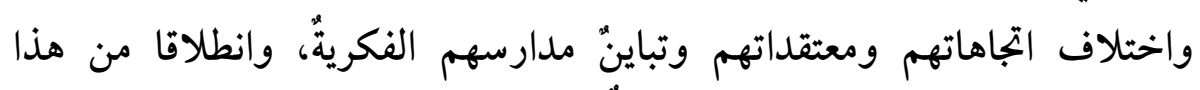
الاختلاف يُّكن أن نقدم التعاريفُ التاليةً:

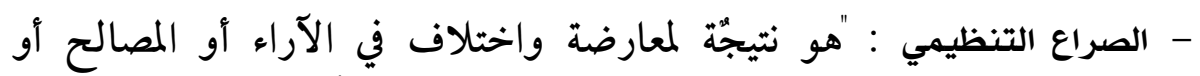

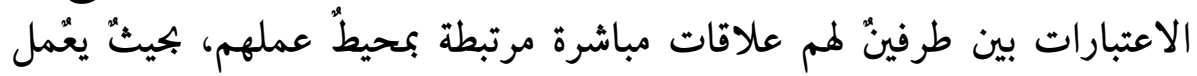

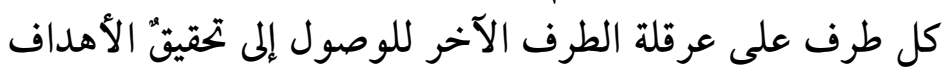

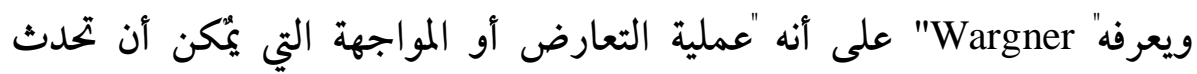

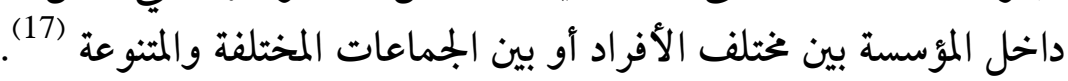

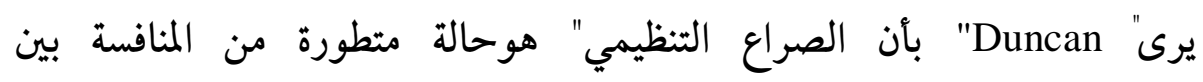

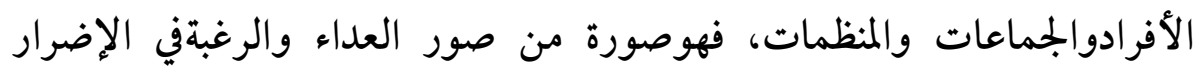

خصائص الصراع التنظيمي : تتمثل خصائص الصراع التنظيمي بما يلي:

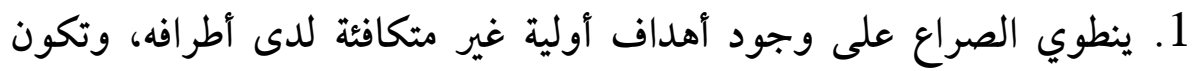

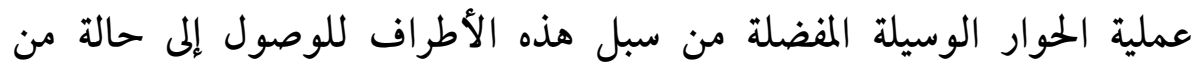
التكافؤ في الأهداف (المصلحة المشتركة). 
2. يعتبر التوتر(Tension) بعداً أساسياً في الصراع، وهو ما يطوي في ثناياه إمكانية

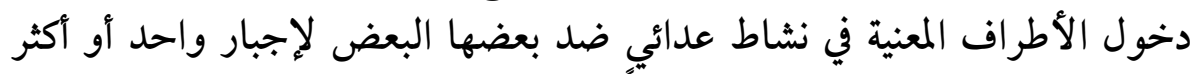

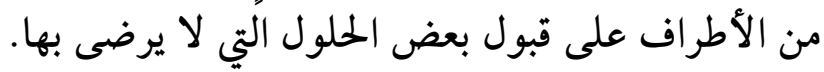

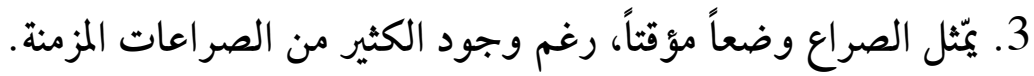

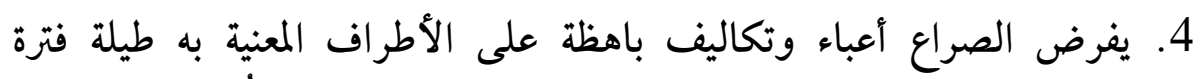

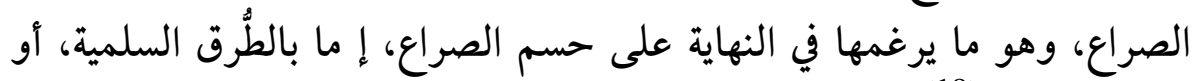
بالقوة القسرية (19) مجالات الصراع التنظيمي :

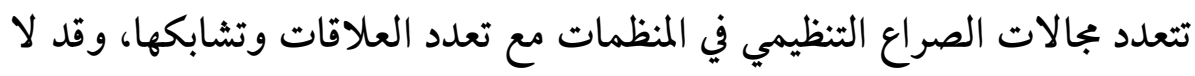

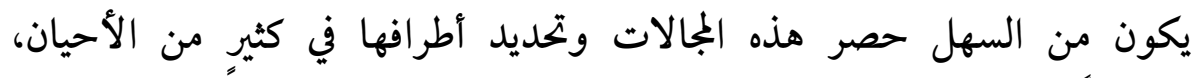

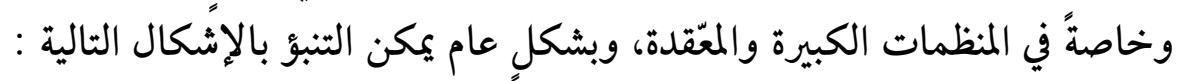

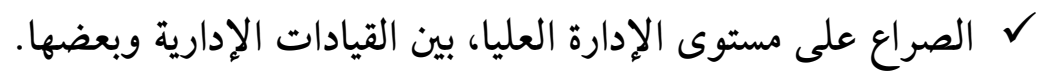

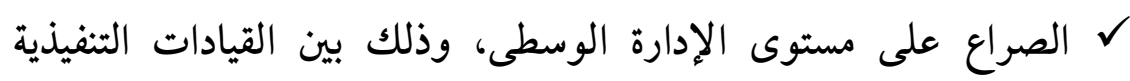
وبعضها.

ل الصراع على مستوى الإدارة الدنيا، وذلك بين القيادات الإشراقية وبعضها، أو بين العاملين وبعضهم.

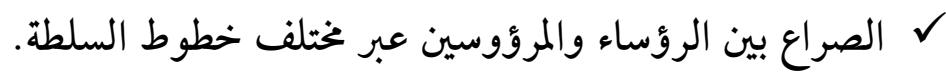
$\checkmark$ ل الصراع بين الإدارة والعاملين في المستويات الدينيا.

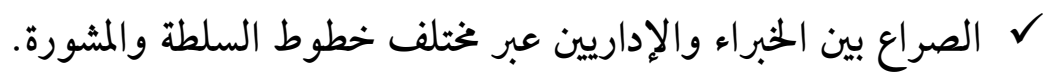

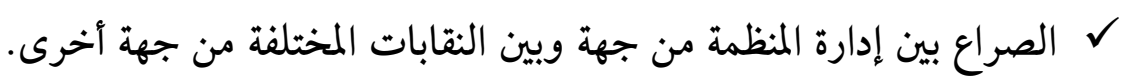
ل الصراع بين المنظمة أو إدارتها وبين جمهور المستفيدين (20). مستويات الصراع التنظيمي : 
بعد استعراض تطور نظرية الصراع التنظيمي سنوضح مستويات الصراع التنظيمي

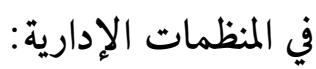

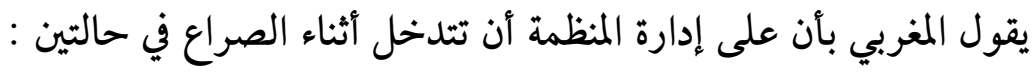

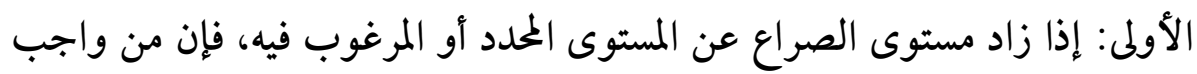

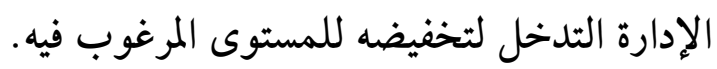

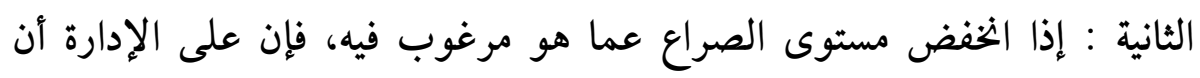

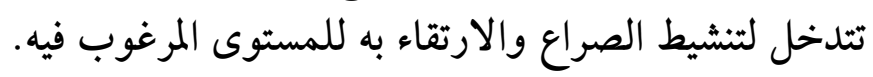
ومما سبق يتضح لنا أن الصراع التنظيمي له ثلاث مستويات:

$$
\begin{aligned}
& \text { 1. مستوى الصراع المرغوب فيه. } \\
& \text { 2. 1. مستوى صراع أعلى من المرغوب فيه. } \\
& \text { 3. مستوى صراع أقل من المرغوب فيه. }
\end{aligned}
$$

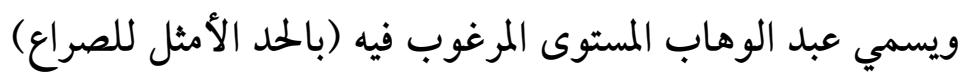

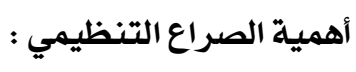
تتمثل أهميةالصراع في بعض النقاطنوجزها التفيهي فيما يلي:

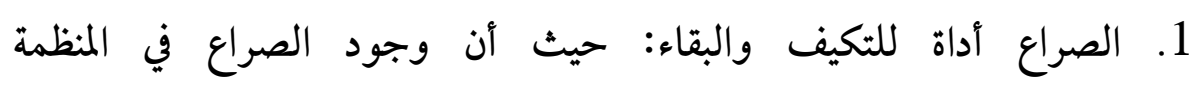

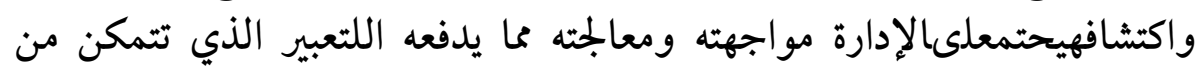
خلاله المنظمة الموائمة والتكيف بهدف استمرار بقائها ونموها

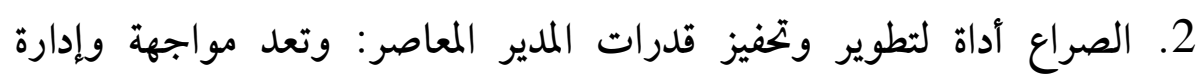

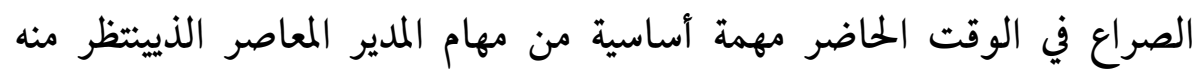

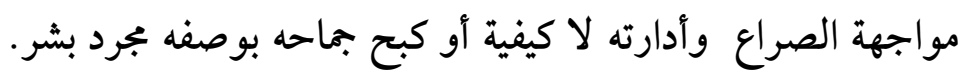

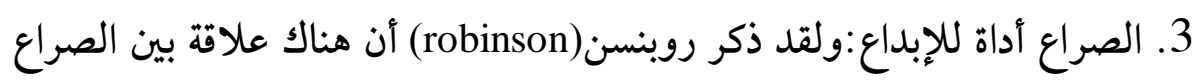

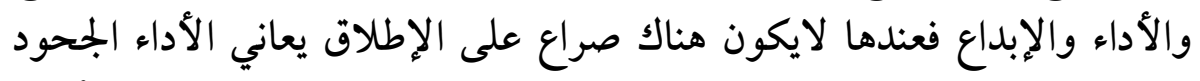

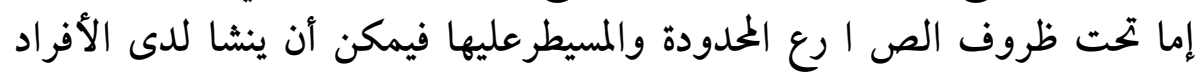

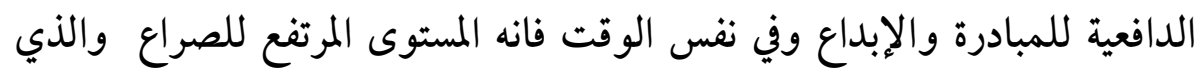


يصف العنف أو عدم التعاون أو اللامبالاة الأمر الذي يؤثر سلبا في الأداء وبالتاليفي الإبداع.

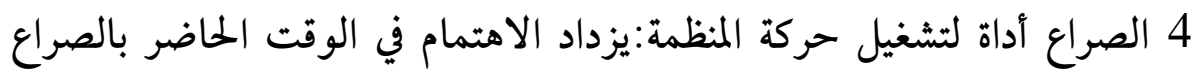

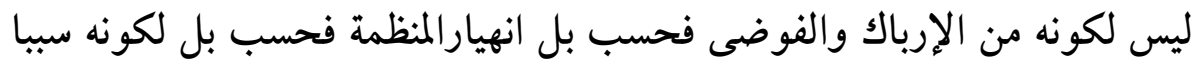

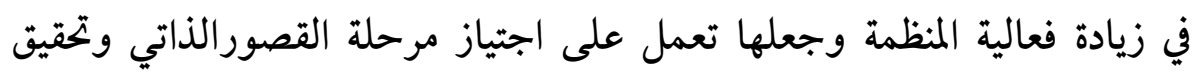

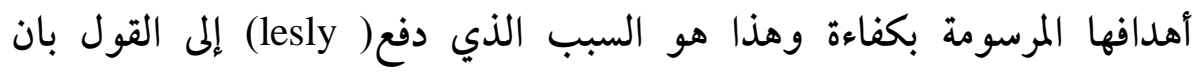

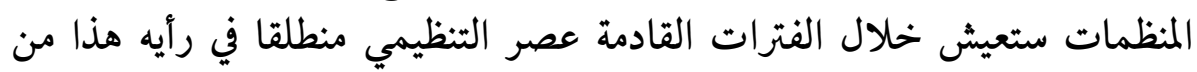

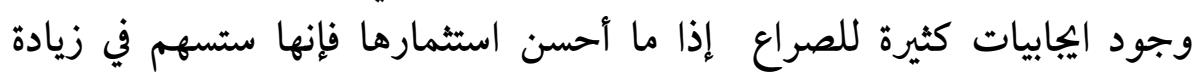
فعالية المنظمة وتمكنها من تجاوزسلبياتها. تجنب الصراع التنظيمي في ظل التنوع في مكان العمل : وهو الأسلوب الذي يحاول المدير عند استعماله المحافظة على التجانس

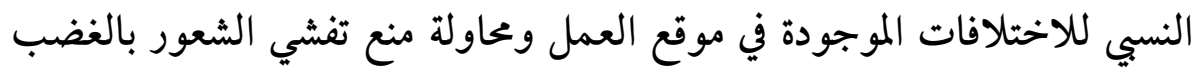

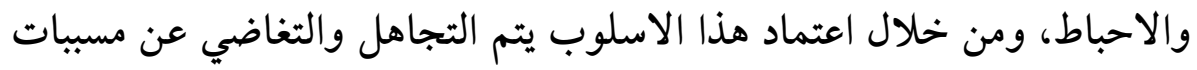

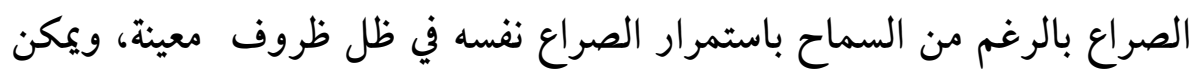

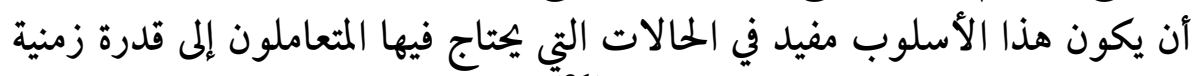
للتفكير والتروي وإعادة النظر في الأمور (21).

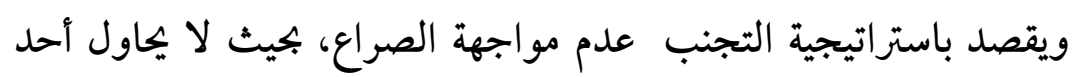

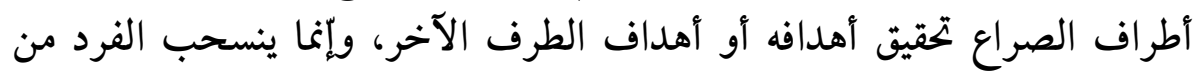

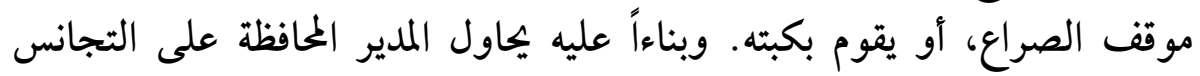

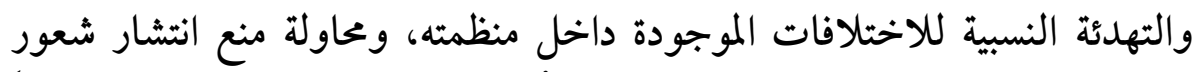

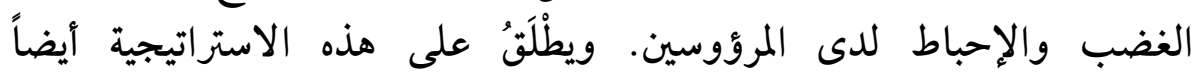

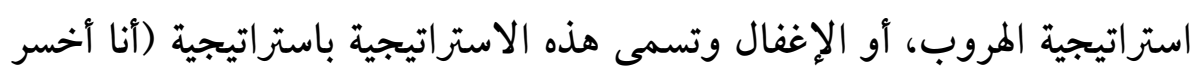

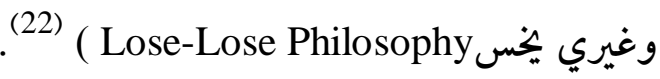


مساهمة مدخل تسيير الصراعات في نجاح ثقافة التنوع في المؤسسة ذات الطابع الدولي : يككن للمؤسسة الاقتصادية عموما والمؤسسات الاقتصادية دولية النشاط أن تواجه عدة مشكلات تنظيمية نابعة من ضعفها في تسيير التنوع لدى الموارد

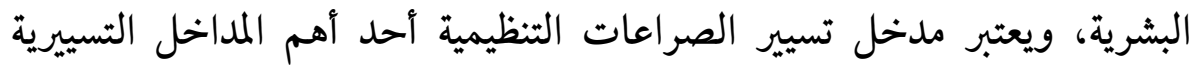

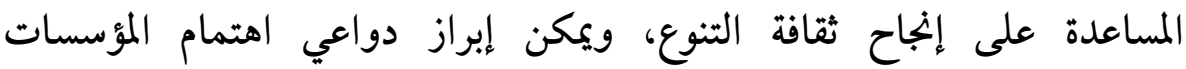

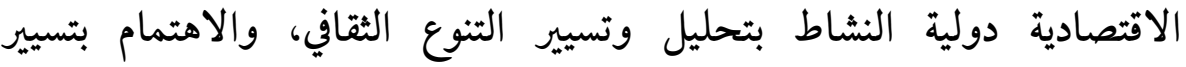
الصراعات الثقافية كالاتي : الإنية * تأثير الاخلاق على ممارسات تسيير الموارد البشرية ومن أهم الممارسات

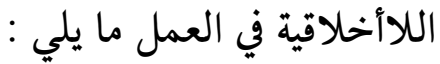

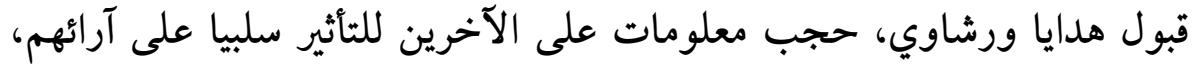

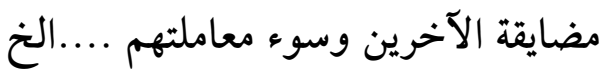

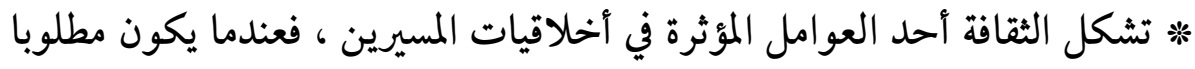

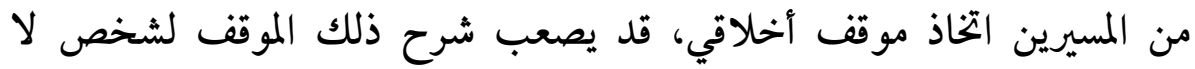

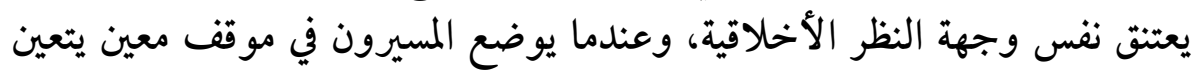

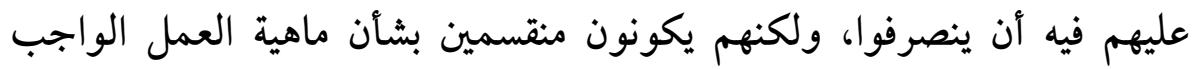

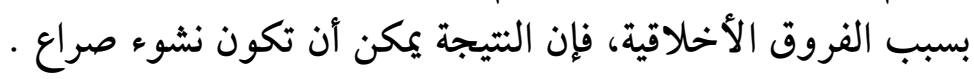

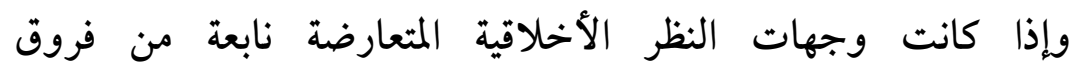

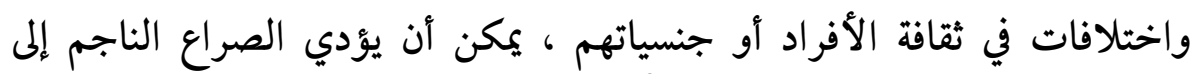
حدوث انقسامات على أسس ثقافية (23)

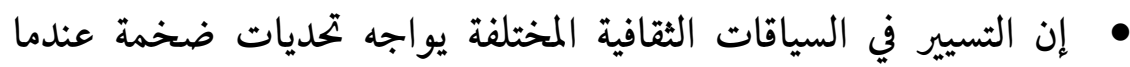

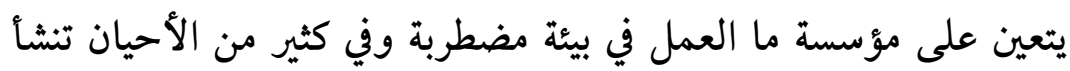

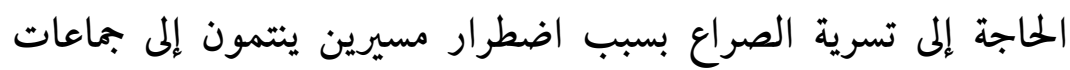

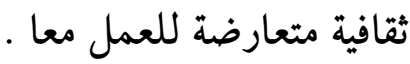


يتبنى الموظفون ثقافة مجموعة المسيرين المسيطرة عند العمل في سياق

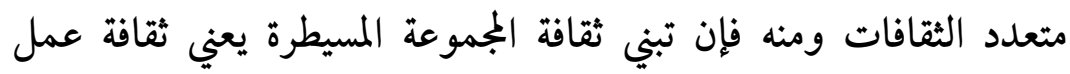

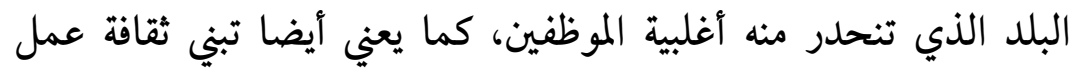

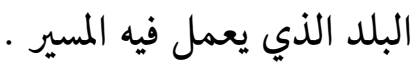

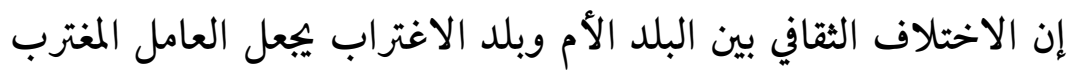
يعاني من اختلاف القيم والعادات والتقاليد بينه وبين بجتمع الاغتراب،

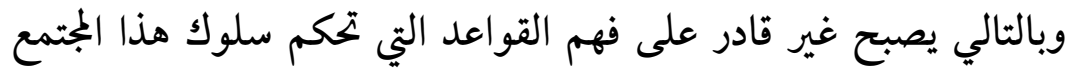

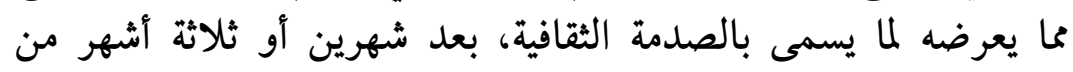

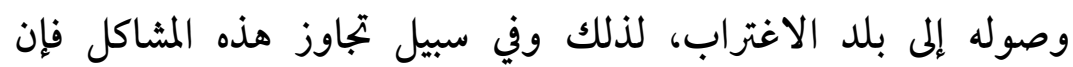

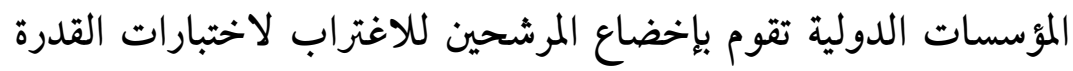

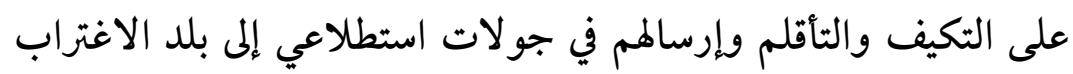
للتعرف عن قرب عن كافة المكونات البيئية .

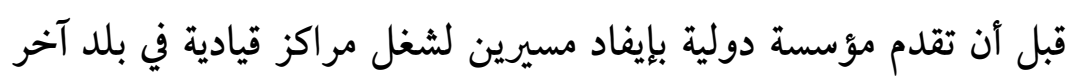

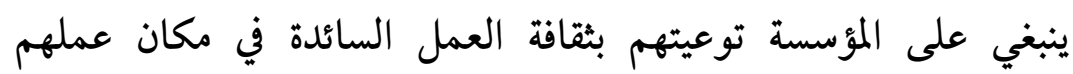
الجديد وتهيئهم ذهنيا للتكيف مع ثثافة العمل السائدة يمكن أن يظهر الصراع بين المسيرين المنتمين إلى ثقافات مختلفة والذين دهين

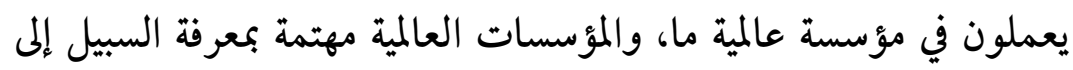

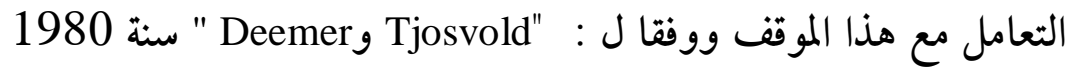

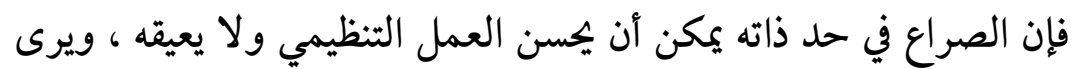

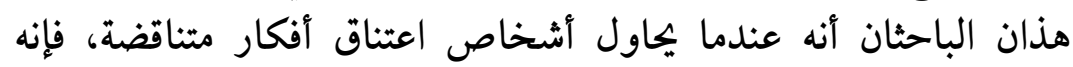

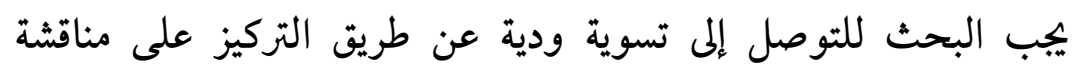

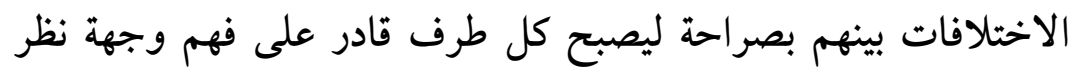
الطرف الآخر . الاخات بينم إن المؤسسات الدولية يمكن أن تبحث إمكانية إنشاء إدارة للتنوع تكون

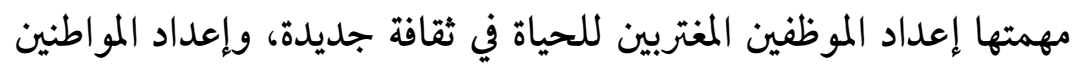


المحليين لتقبل الموظفين المغتربين القادمين من ثقافات أخرى بالإضافة إلى

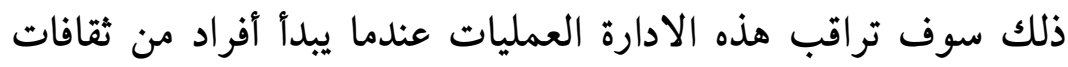

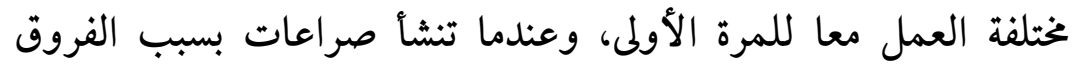

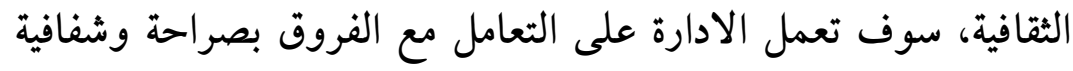

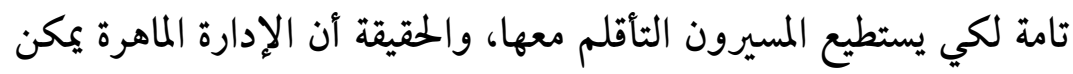

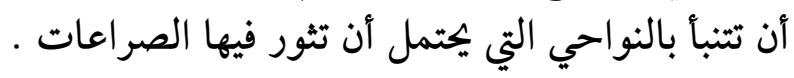

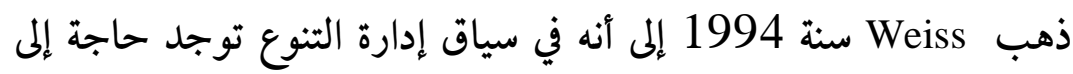

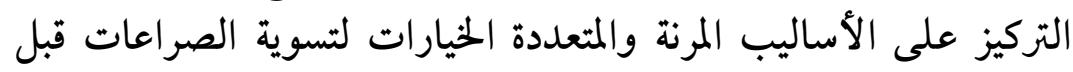

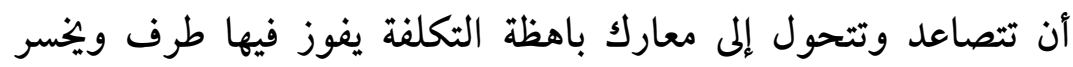
الآخر أو يخسر الطرفان.

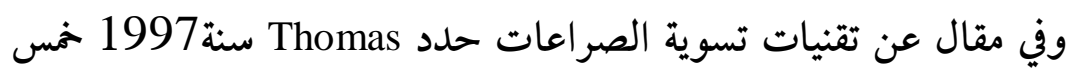

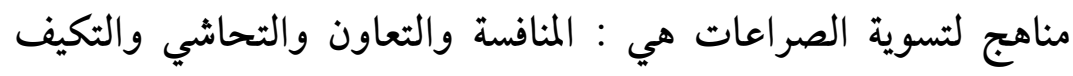

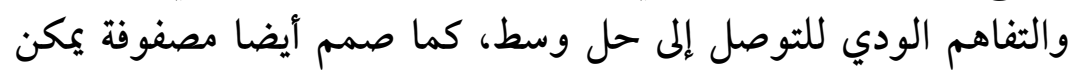

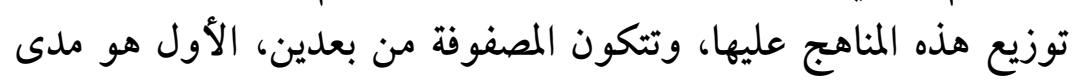

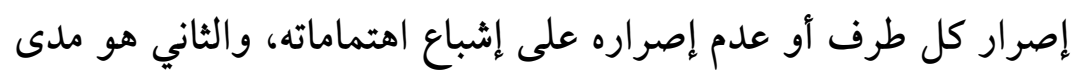

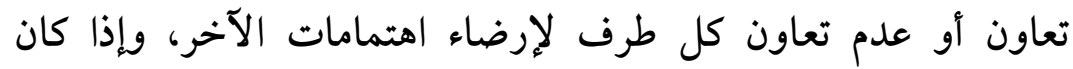

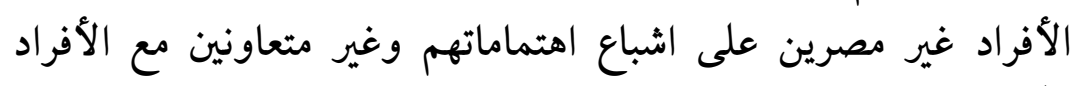

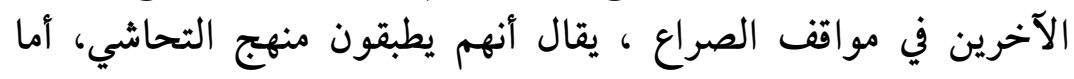

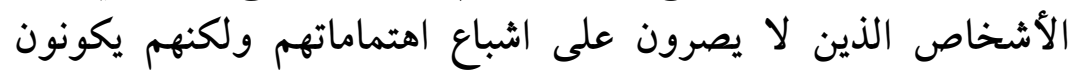

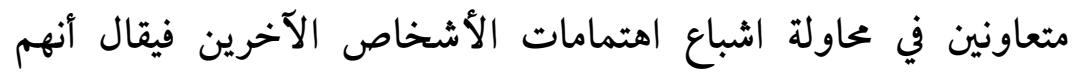

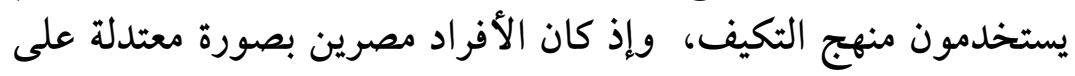

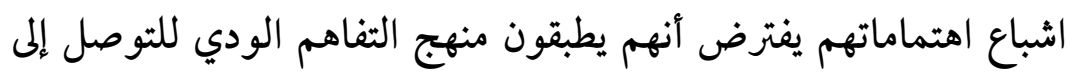

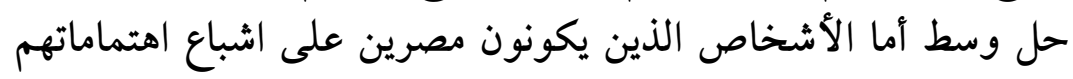
ومتعاونين أيضا فيقال أنهم يستخدمون منهج الإن يكون مصرين على التعاون. 
وأخيرا فإن الأشخاص الذين يكونون مصرين على اشباع اهتماماتهم

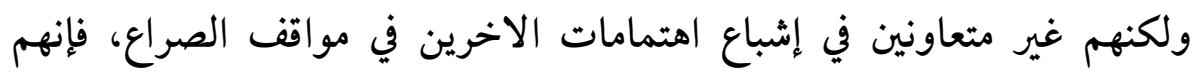

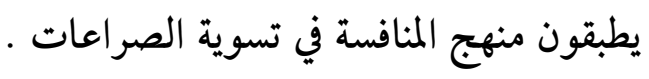

إن المسيرين العالميين في تسوية الصراعات الناجمة عن تعارض وجنات الماتهات

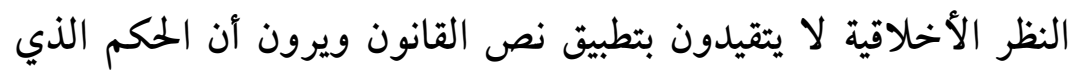

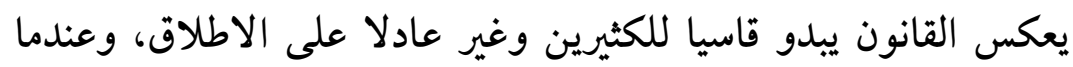

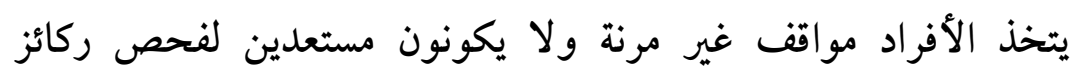

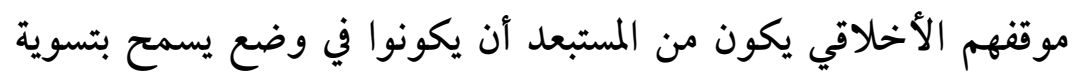

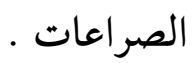

> في كل ثقافة يوجد مسيرون يتخذون مواقف أخلاقية متصلبة وغير مرنة،

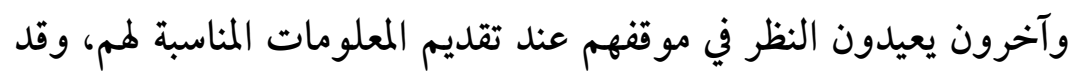

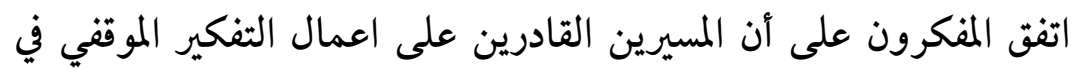

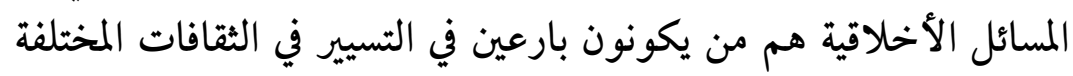

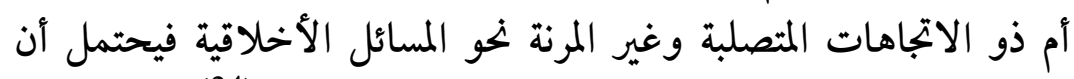
يتورطوا في مواقف الصراع عند العمل في ثقافات أجنبية (24).

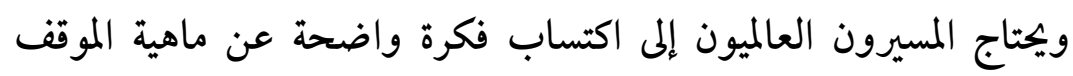

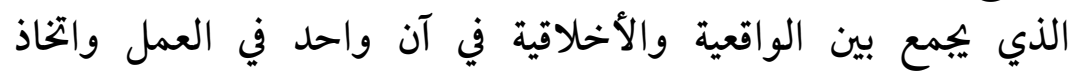

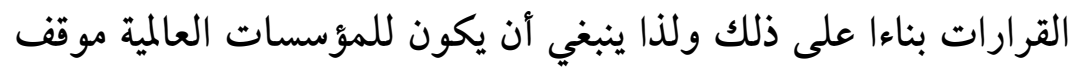

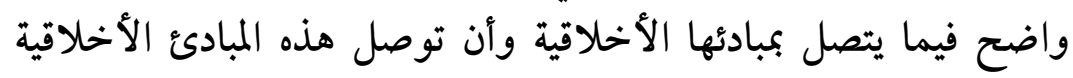

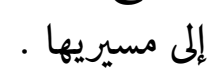

خصائص وصفات المسير الدولي في مجال تسيير الصراعات الثقافية : من أهم خصائص وصفات المسير الدولي في مجال تسيير الصراعات الثقافية ما يلي : الثم 1. القدرة على التكيف مع الفروقات الثقافية . 
2. الاستقلالية والاعتماد على النفس.

3. الصحة الجسدية والعاطفية التي تمكن المسير الدولي من مواجهة تحديات البيئة.

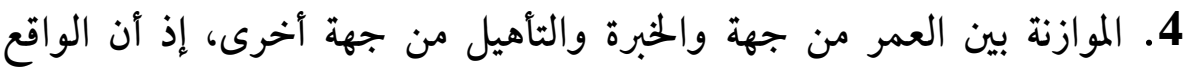

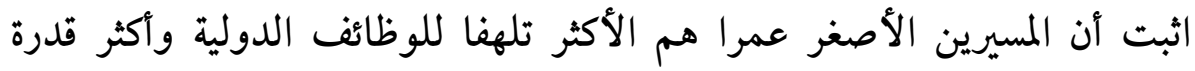

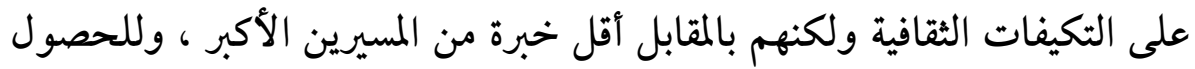

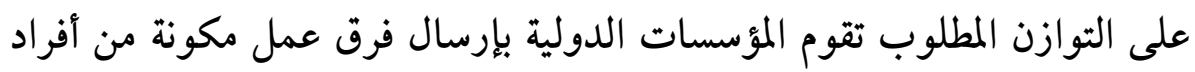
من أعمار مختلفة ( التنوع في الفئات العمرية ) . 5. المهارات اللغوية إذ أنه عل الرغممن أن اللغة الإنجليزية هي اللغة الأساسية في

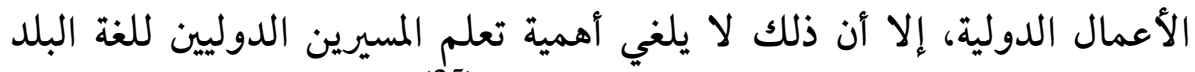

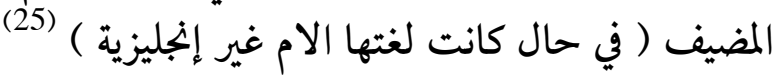

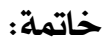

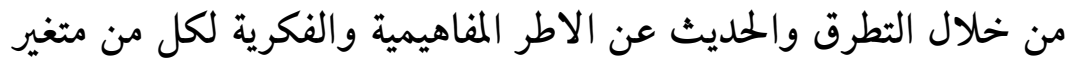

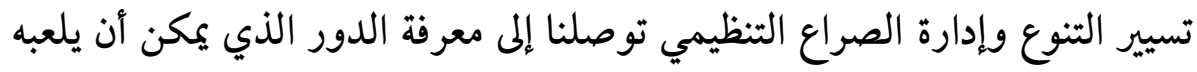

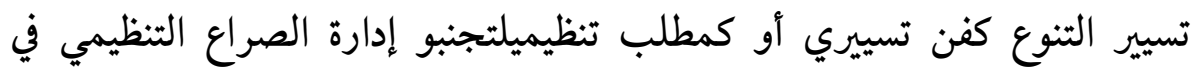

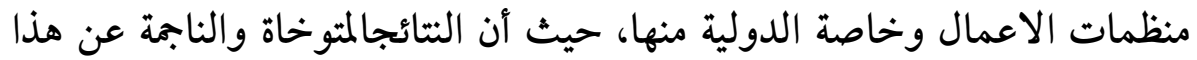

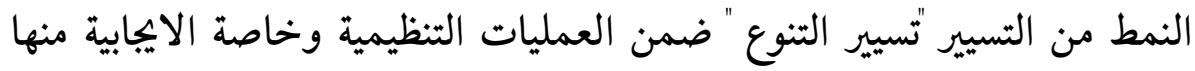

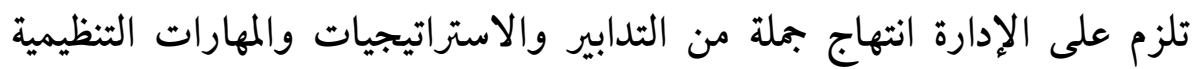
بهدف التقليل من السلبيات والوصول إلى القداج أقصى حد من الإييابيات وتسخيرها

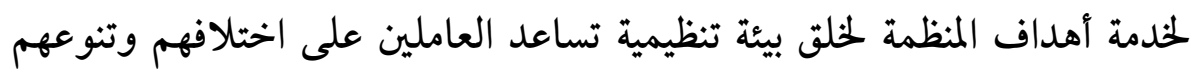

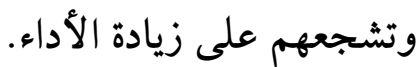

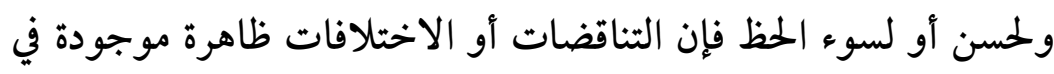

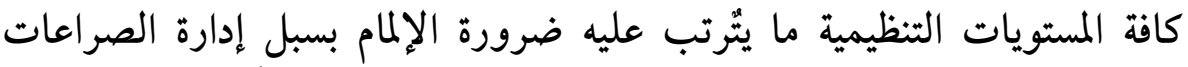

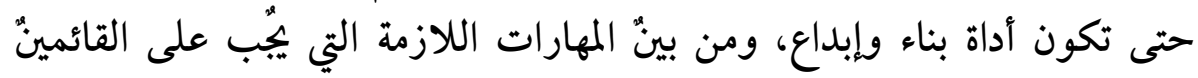

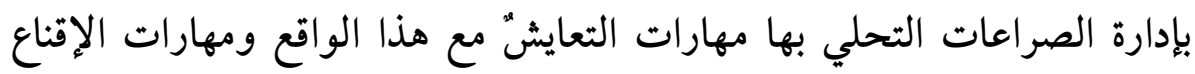




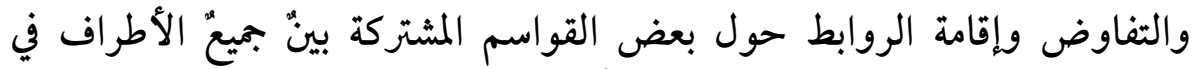

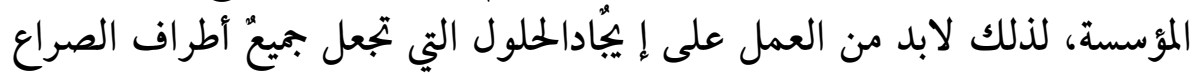

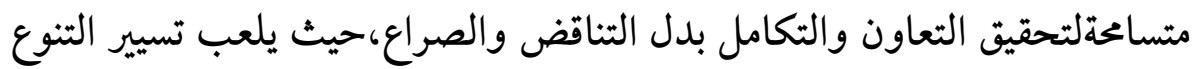

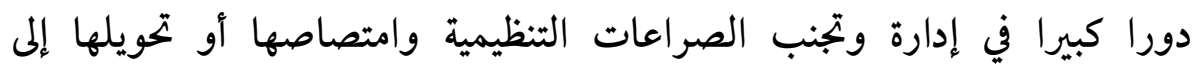

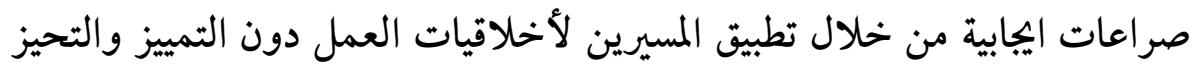
بين العاملين.

وبالتالي ترسيخ قيم العدالة التنظيمية وتقبل الآخر في ظل مبدا تكافؤ

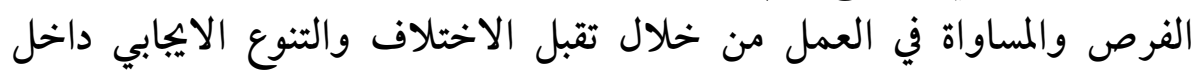
مكان العمل ، فالتنوع كآلية تسييرية له دور كبير في تجنب الصراع وتسئل وتسييره في منظمات الأعمال التي تعمل في بيئات مختلفة وتوظف التف عمالة متنوعة، وحتى دئى

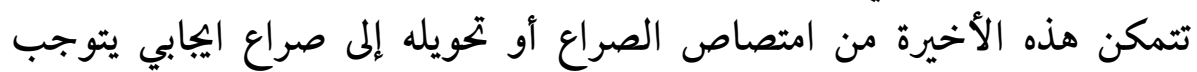

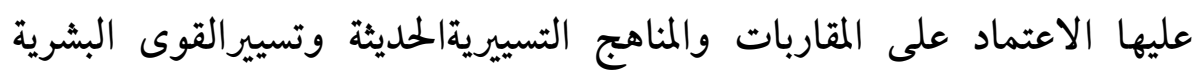
والاستفادة القصوى من قدرات العاملين وإمكانياتهم على اختى إتلافهم وتبادين

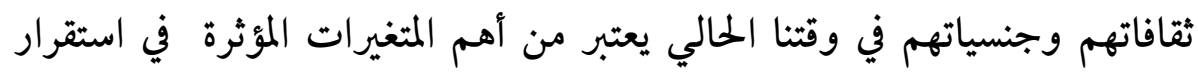

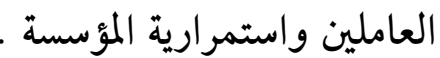

\section{هوامش البحث}

(1) Hédiazannad et pete stone, «mesurer la diversité en entreprise :pour quoi et comment ? », revue management et avenir, vol 38, France, 2007, p159.

(2) Claudia Hoge : Cultura diversity in organizations, Master thesis, Unbruka University, school of management , 2003, p 8 -9.

(3) Nigel Bassett - jones : The Paradox of Diversity Management ,Creativity and innovation, CREATIVITY AND INNOVATION MANAGEMENT ? Black well Publishing Ltd, Volume 14 Number 2 2005, p 170. 
(4) CHAPTER 10 : Diversity Management . Paradigmes .Rationale , and Key ELements,p 248- 249 , available on : www. sagepub .com/upm- data/35190 - Chapter 10. Pdf,P236.

(5) Lutz

Tilker

:ManaginDiversity

Attainingcompetitiveadvantagethroughdiversity , Spencer Stuart ,FrankFurtpencer, 2003,p9.

(6) Kossek ,Ellen Ernst : Zonia ,Susan C, ; Young , Williard ,The limitations, of organizational demography : Can diversityclimatebeenhanced in the absence of teamwork ?, (Ed), 1996 ,Selected research on work team diversity , p 121 - 150 , Washington, DC, US : American Psychological Association, vii p 184.

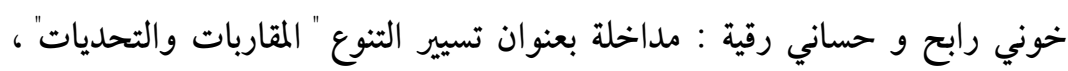

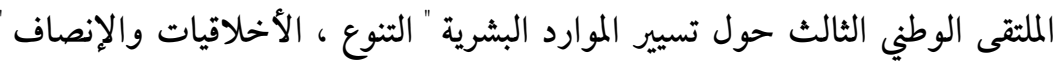
نظرة حول ممارسة تسيير الموارد البشرية في المؤسسات الجزائرية يومي 25 - 26

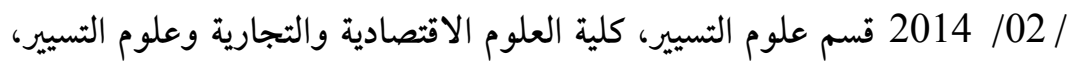

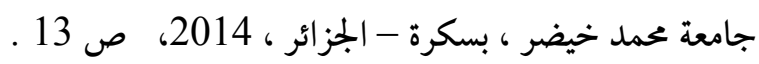

(8) CHAPTER 10 ; op cit, p 244.

جيرالد جرينبيرج و روبيرد بارون: إدارة السلوك في المنظمات ترجمة رفاعي محمد و

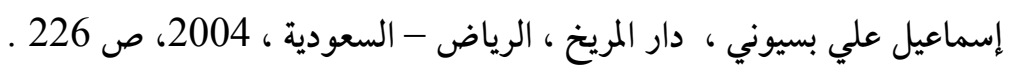

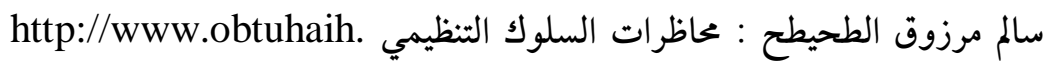

.Com / moodle

حمدي الإمام محمد أحمد : إدارة التنوع في القوة العاملة في ظل الفكر الإداري http://faculty.ksu.edu.sa، التقليدي والحديث 


$$
\begin{aligned}
& \text { منير نوري و فريد كورتل: إدارة الموارد البشرية ، ط1، مكتبة المجتمع العربي للنشر }
\end{aligned}
$$

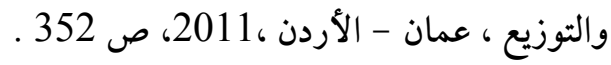

(13) Gary Collins, Yamil H. Alonso :« WORKPLACE DIVERSITY: AN EMPLOYER'S GUIDE FOR BUSINESS ADVANTAGE », The Brampton Board of Trade, Canada, 2012, p. 4..

$$
\text { حمدي الإمام محمد أحمد : مرجع سابق . }
$$

(15) PninaShachaf: Cultural diversity and information and communication technology impacts on global virtual teams: an exploratory study, School of Library and Information Science,Indiana University, Bloomington,2008, P 3.

(16) Ralph Ramirez, « Diversity in The Workplace », CCT,CEH, USA, 2010, p. 5.

بورغدة حسين: إدارةالصراعاتالتنيمية، مجلة العلوم الاقتصادية وعلوم التسيير،

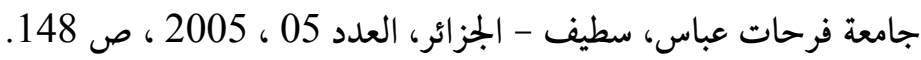

سامية فتحي عفيف و كاميليا يوسف الجنايني: الاتجاهات الحديثّة في السلوك

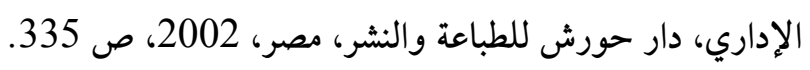

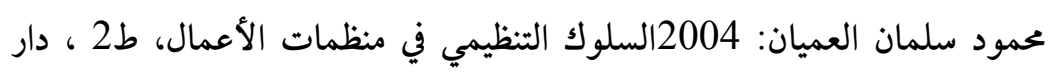

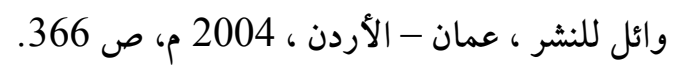

أحمد يوسف أحمد اللوح: الصراعات التنظيمية وانعكاساتها على الرضا الوظيفي

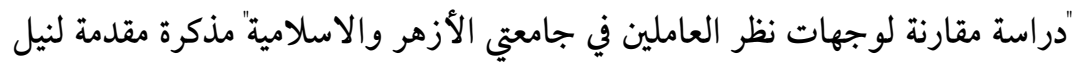
شهادة الماجستير في إدارة الأعمال، كلية التجارة، الجامعة الاسلامية بغزة، 2008، العامين

امل محمود علي العبيدي: استراتيجية الصراع التنظيمي وإمكانية تحقيق أهداف

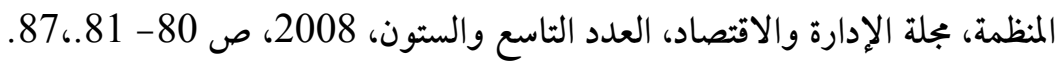




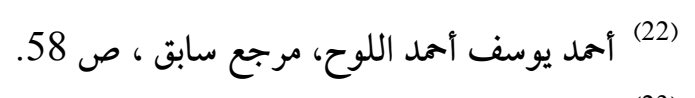

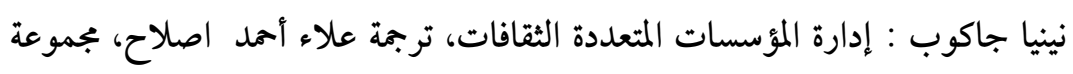

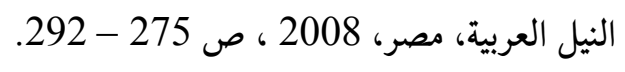

حسان المتني : إدارة الموارد البشرية الدولية، بدون ذكر دار نشر ، سوريا، 2700 ، 2009 ، ص

$$
\text { . } 8-6
$$

يونس الزين وبوبكر عباسي: مداخلة بعنوان "الثمكين وتسيير الصراعات التنظيمية

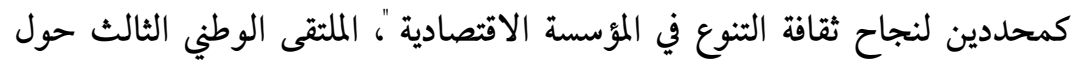

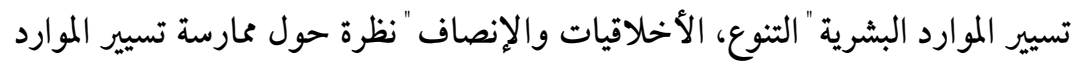

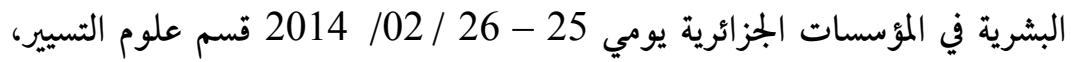
كلية العلوم الاقتصادية والتجارية وعلوم التسيير، جامعة محمد خيضر، بسكرة -

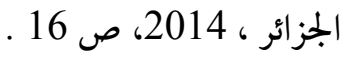

